\title{
Biological, behavioral, and relational levels of resilience in the context of risk for early childhood behavior problems
}

\author{
SUSAN D. CALKINS, ALYSIA Y. BLANDON, AMANDA P. WILLIFORD, \\ AND SUSAN P. KEANE
}

University of North Carolina at Greensboro

\begin{abstract}
Longitudinal growth patterns of internalizing and externalizing behavior problems were examined in a community sample of 441 children across the ages of 2 to 5 using hierarchical linear modeling. Contextual risk was measured using fiveindicators (socioeconomic status, marital status, number of siblings, parent stress, parent psychopathology), and three levels of child resilience (biological, behavioral, and relational) were also assessed. Results indicate that a general pattern of decline in both types of behavior problems was observed for the entire sample across time, although considerableindividual variability in this pattern was observed. Children's externalizing and internalizing behavior at age 5 was predicted by the level of risk at age 2. All three child resilience factors were also predictive of externalizing and internalizing behaviors at age 5. In the prediction of the slope of problem behavior over time, risk status interacted with both temperamental fearlessness and a mutually responsive orientation with the mother to predict the decline in externalizing and internalizing problem behavior. Results underscore the complex interactions of risk and multiple levels of resilience that are implicated in the maintenance of problem behavior over time. They highlight the importance of considering whether expected resilience factors operate similarly across different levels of risk.
\end{abstract}

The study of childhood adjustment difficulties has focused on two broad sets of behavioral problems: those characterized by aggression and acting-out behaviors (externalizing problems), and those characterized by anxiety, withdrawal, and depression (internalizing problems; Achenbach, 1991, 1992; Achenbach \& Edelbrock, 1983). Early childhood behavior problems are of interest to clinicians and researchers alike because of their influence on concurrent psychological and social functioning (Campbell, 2002),

This research was supported by a National Institute of Mental Health (NIMH) Behavioral Science Track Award for Rapid Transition (MH 55625), an NIMH FIRST Award (MH 55584) and an NIMH K-Award (MH 74077) to Susan D. Calkins, and an NIMH Grant (MH 58144) awarded to Susan D. Calkins and Susan P. Keane.

Address correspondence and reprint requests to: Susan D. Calkins, Department of Psychology, University of North Carolina at Greensboro, Greensboro, NC 27402; E-mail: sdcalkin@uncg.edu. their role in influencing later functioning across peer and school contexts (Keane \& Calkins, 2004; Rubin, Coplan, Fox, \& Calkins, 1995), and their potential to constrain the development of a range of emotional, cognitive, and social skills (Calkins \& Fox, 2002; Nigg \& HuangPollock, 2003). Moreover, both kinds of problems are associated with a range of contextual risk factors that increase the likelihood that a child will exhibit symptoms of adjustment difficulties (Owens \& Shaw, 2003; Sameroff, Gutman, \& Peck, 2003). Recent work on trajectories of problem behaviors reinforces the notion that there are multiple possible pathways that may be observed (Broidy et al., 2003; Nagin \& Tremblay, 1999) and that multiple factors may contribute to these pathways (Shaw, Gilliom, Ingoldsby, \& Nagin, 2003). These observations suggest that identifying the risk and protective factors that may alter individual trajectories is of significance. 
Conceptual and empirical work on risk and protective factors in early emerging behavior problems is often conducted from within a developmental psychopathology framework (Calkins \& Fox, 2002). Such a perspective suggests that there are multiple contributors to maladaptive and adaptive outcomes, that these contributors may interact in various ways within different individuals, and that the consequences for development are multiple pathways to disordered behavior and/or multiple variants of outcome from individual causative factors (Cicchetti, 1984, 1993; Cicchetti \& Rogosch, 1996; Sroufe \& Rutter, 1984). Cicchetti and others (Cicchetti \& Rogosch, 1996; Richters, 1997) have described these perspectives as multifinality and equifinality. Such a perspective emphasizes the importance of conducting longitudinal investigations of the multiple forces that may both influence and be influenced by early contextual, familial, or individual difference factors.

A developmental psychopathology perspective also has implications for understanding through what process or processes children's early problematic behavior is ameliorated or maintained. This perspective also stimulates an interest in resilience, or the role of protective factors, particularly in the empirical examination of those features of either the child or the environment that may alter the developmental pathway such that adjustment, rather than maladjustment, is possible (Luthar, Cicchetti, \& Becker, 2000; Masten, Best, \& Garmezy, 1990; Rutter, 1987). Finally, a developmental psychopathology perspective advocates an organizational view of development; thus, multiple factors, or levels of a given factor, are considered in the context of one another, rather than in isolation (Cicchetti \& Dawson, 2002).

In applying a developmental psychopathology perspective to the study of risk and protective factors implicated in early behavior problems, researchers have examined numerous child, environmental, and contextual factors that serve to protect against poor behavioral adaptation in the context of adversity (Owens \& Shaw, 2003; Seifer, 2003). A more fine-grained approach is to consider the multiple levels that may exist within each of these broad child, family, and contextual resilience factors. For example, the individual child factors may operate in an integrated system that consists of multiple, increasingly differentiated levels of functioning that can be studied by examining simultaneously the biological, behavioral, and social processes that contribute to adaptive behavior (Calkins \& Fox, 2002; Posner \& Rothbart, 2000). Here, we address several levels of child functioning that may serve as resilience factors through their role in either decreasing the likelihood of maintaining, or exacerbating, early externalizing and internalizing behavior problems among children at risk for such difficulties.

\section{Early Broad Spectrum Externalizing and Internalizing Problems}

Considerable research has demonstrated that early-onset externalizing behavior problems, characterized by aggressive, destructive, and oppositional behaviors, are risk factors for the development of later, more serious problems such as conduct disorder, attention-deficit/ hyperactivity disorder, and juvenile delinquency (see Campbell, 2002; Campbell, Shaw, \& Gilliom, 2000, for reviews). Traditionally, it was thought that as young children acquire more cognitive, language, and regulatory skills, they are better able to cope with developmental challenges and outgrow externalizing behavior problems (Campbell, 2002; Kopp, 1982). In fact, research has shown a normative developmental pathway of externalizing behavior problems that peaks at age 2 and that shows a distinct decline with age (Hartup, 1974; Tremblay, 2000). Although it may be the case that most children acquire adaptive skills that help them manage challenging situations in appropriate and constructive ways (Hartup, 1996; Tremblay, 2000), for some children, early-onset externalizing problems remain stable and lead to more serious maladaptive outcomes (Campbell, 2002; Cummings, Ianotti, \& zahn-Waxler, 1989). Therefore, it is important to identify the factors that contribute to different patterns of externalizing problem behavior across early childhood.

Internalizing spectrum behavior includes social withdrawal, inhibition, shyness, anxiety, and depression (Achenbach \& Edelbrock, 1981; Rubin \& Asendorpf, 1993; zahn-Waxler, 
Klimes-Dougan, \& Slattery, 2000). Much of the early research linking child characteristics to internalizing behavior problems focused on the phenomena of behavioral inhibition to the unfamiliar. Behavioral inhibition captures a child's initial response to novel events or unfamiliar adults. First described by Kagan and colleagues (Garcia-Coll, Kagan, \& Reznick, 1984; Kagan \& Snidman, 1991), this research indicated that infants and young children who are behaviorally inhibited display low approach tendencies, become and remain vigilant for the duration of exposure to the novel object, and often seek the proximity of a caregiver when exposed to novel events or situations. The consequence of an early inhibited behavioral style appears to be social withdrawal, one index of internalizing difficulties (Fox et al., 1995). Children with these difficulties often continue to have problems that may escalate into significant anxiety disorders or depression (Biederman et al., 2001; Ollendick, Shortt, \& Sander, 2005), again reinforcing the notion that identification of risk and protective factors across the early period of development is of high significance.

Risk for behavior problems has been examined in a number of studies (for reviews, see Campbell et al., 2000; Cummings, Davies, \& Campbell, 2000; Rutter, 2002). Of interest have been factors that are broadly clustered into categories of contextual, familial, and child risk, and that include a wide range of factors, including socioeconomic status (SES), family size, marital status, parent psychological functioning, maltreatment, prematurity, genes, and child temperament (Owens \& Shaw, 2003; Seifer, 2003). Sociodemographic factors play an especially important role in the emergence and maintenance of problem behavior in early childhood (McLoyd, 1990). Poverty, for example, has both direct and indirect effects on children's development. Poor economic circumstances are likely to increase the psychological distress experienced by parents that in turn affects how parents interact with their children. The most common parental response to increased psychological stress is an increased use of coercive discipline techniques, behavior that is directly implicated in increases in child problem behavior (Campbell, 1995; McLoyd, 1990). Sociodemographic factors also have the effect of limiting choices that parents have about where they live, where their children are educated, and what social and recreational opportunities they may have. Stress associated with parenting has also been implicated in the development and maintenance of behavior problems (Barkley, 1990). Considerable attention has been directed toward the influence of parental psychological functioning and child development. In particular, maternal psychopathology, specifically depression, has been linked to the manifestation of externalizing-type behaviors in children (Anastopoulos, Guevremont, Shelton, \& DuPaul, 1992; Cummings, 1995; Seifer, Schiller, Sameroff, Resnick, \& Riordan, 1996).

Sameroff and colleagues (2003) have argued for an approach to the study of risk that acknowledges that risk factors tend to cluster, and that it is the accumulation of adversity that connotes risk. Here, we adopt such an approach and focus on several contextual factors that have been previously linked to the development of early internalizing and externalizing behavior problems and that are readily observable in community samples of young children (SES, family size, marital status, and parent functioning, including both psychopathology and stress). In reviewing the extant research on child factors that may serve to offset these risks and provide insight into the resilience process that may be operating across levels of child functioning, several candidate factors emerge; we focus on the biological, behavioral, and relational levels of child functioning given evidence that each factor has known associations to positive outcomes and adaptation.

Child Resilience Factors: Biology,

Behavior, and Relationships

\section{Biological characteristics}

In both the child and adult personality and psychopathology literature, a number of studies suggest links between biological functioning and psychopathology, and from both a risk and resilience perspective (Crowell et al., 2006; Curtis \& Cicchetti, 2003; Rottenberg, Salomon, Gross, \& Gotlib, 2005). We focus on the important 
of biological functioning in the development of adaptive behavior, particularly well-regulated emotion and behavior, as a resilience mechanismin both internalizing and externalizing problems (Calkins \& Dedmon, 2000; Calkins, Graziano, \& Keane, in press; Calkins \& Keane, 2004). We follow Porges' polyvagal theory (Porges, 1996, 2001, 2003; Porges, Doussard-Roosevelt, \& Maita, 1994), which describes the function of biological maturation, specifically maturation of the parasympathetic nervous system that plays a key role in regulation of state, motor activity, and emotion. Porges notes that individual differences in nervous system functioning might mediate the expression and regulation of emotion and, by extension, might be an important element of the system that supports appropriate social engagement and positive adjustment (Porges, 2001, 2003; Porges et al., 1994).

Porges and others have found that parasympathetic nervous system functioning, as reflected in heart rate variability influenced by the vagal system, is related to the control of attention, emotion, and behavior (Calkins, 1997; Calkins \& Dedmon, 2000; DeGangi, DiPietro, Greenspan, \& Porges, 1991; Huffman et al., 1998; Porges, Doussard-Roosevelt, Portales, \& Greenspan, 1996). Although there are multiple ways to measure this variability, Porges (1985, 1991, 1996) and colleagues developed a method that measures the amplitude and period of the oscillations associated with inhalation and exhalation. This measure refers to the variability in heart rate that occurs at the frequency of breathing (respiratory sinus arrhythmia [RSA]), and is thought to reflect the parasympathetic influence on heart rate variability via the vagus nerve. Levels of baseline, or resting, vagal tone are considered to be a stable neurophysiological mechanism underlying autonomic and behavioral reactivity potential in the absence of environmental challenge. For example, high resting RSA has been associated with appropriate emotional reactivity (Stifter \& Fox, 1990) and good attentional ability (Richards, 1987; Suess, Porges, \& Plude, 1994).

Porges' theory further suggests that the RSA measure is sensitive to changes in the organism in response to environmental challenge. During situations where active coping or emotional and behavioral regulation is required, the vagal input to the heart is withdrawn and a decrease in RSA is observed, a response that results in greater cardiac output in the form of heart rate acceleration that supports the coping response. Thus, this response is a physiological indicator of the individual's ability to engage in appropriate regulatory behavior (Porges, 2001, 2003). Evidence of vagal withdrawal during demanding tasks, as indexed by a decrease in the RSA measure, may reflect physiological processes that allow the child to shift focus from internal homeostatic demands to demands that require internal processing or the generation of coping strategies to control affective or behavioral arousal. In sum, vagal withdrawal is thought to be a physiological strategy that permits sustained attention and behaviors indicative of active coping that are mediated by the parasympathetic nervous system (Porges, 1991, 1996; Wilson \& Gottman, 1996).

Considerable research indicates that greater vagal withdrawal, as measured by a decrease in RSA, during challenging situations is related to better state regulation, greater self-soothing and more attentional control in infancy (DeGangi et al., 1991; Huffman et al., 1998), fewer behavior problems and more appropriate emotion regulation in preschool children (Calkins, 1997; Calkins \& Dedmon, 2000; Calkins \& Keane, 2004; Porges et al., 1996), and sustained attention in school-age children (Suess et al., 1994). Moreover, recent research comparing the magnitude of RSA response to different types of challenges indicate that children display significantly greater decreases in RSA when provided with parental support during a task than when confronted with a challenge independent of support (Calkins \& Keane, 2004), and that the magnitude of this response is an individual difference that is moderately stable across early development and that predicts a range of indicators of adaptive functioning (Calkins \& Keane, 2004; El-Sheikh, 2005).

\section{Behavioral characteristics}

The emphasis on infant and child behavioral characteristics, or temperament, as a predictor of childhood psychopathology grew largely out of basic research in developmental psychology, 
demonstrating that considerable variability existed in children's behavioral style, and that this variability could influence a range of possible experiences the child would have in the course of development (Rothbart \& Bates, 1998). Although temperament is traditionally viewed as consisting of biologically based behavioral traits, its manifestation in behavioral patterns is of interest because it is such patterns that influence children's interactions in the world, and to which parents, teachers, and peers respond, and it is these behaviors that may become integrated into patterns of social and emotional functioning that are problematic (Calkins, 1994).

Negative emotionality is one dimension of temperament that has been linked to both externalizing and internalizing spectrum problems (Rothbart \& Bates, 1998). An extensive body of work has examined the construct of negative emotionality construed as difficultness and anger proneness as a predictor of externalizing problems (Rothbart \& Bates, 1998). This body of work has been conducted in several different countries, with both boys and girls, using different measurement tools. These studies are consistent in finding modest direct effects of these early temperament dimensions on the display of externalizing or acting-out behavior problems at later ages (Calkins \& Dedmon, 2000; Caspi, Henry, McGee, Moffitt, \& Silva, 1995; Prior, Smart, Sanson, \& Oberklaid, 1993; Shaw, Owens, Giovanelli, \& Winslow, 2001).

Researchers have also found that negative temperamental reactivity early in development is related to internalizing behavior in childhood (Keenan, Shaw, Delliquadri, Giovannelli, \& Walsh, 1998; Merikangas, Swendsen, Preisig, \& Chazan, 1998). Other research has found that withdrawal behavior (Mun, Fitzgerald, Von Eye, Puttler, \& zucker, 2001) and irritable distress (Morris et al., 2002) were predictive of internalizing behavior problems in children. Moreover, Mathijssen and colleagues found that children with an easy temperament had fewer internalizing behavior problems (Mathijssen, Koot, \& Verhulst, 1999). Indeed, children's levels of positive affect or sociability have been found to predict lower self-reported anxiety and depression (Phillips, Lonigan, Driscoll, \& Hooe, 2002). In addition, Anthony, Lonigan, Hooe, and Phillips (2002) found that a child composite of negative temperamental traits was related to more child depression and anxiety, whereas a child composite of positive temperamental traits was related to less child depression.

Thus, various measures of negative affectivity seem to be associated with the experiences of anxiety and depression, and with the tendency to act out and behave aggressively. It may also be the case that other temperament dimensions such as persistence, adaptability, and positive affect may protect children against the development of problem behavior (Keiley, Lofthouse, Bates, Dodge, \& Pettit, 2003; St. Jonn Seed \& Weiss, 2002). One issue that is in need of clarification is whether anger versus fear differentially predicts internalizing versus externalizing problems (Calkins \& Fox, 2002) and whether children who are low on these negative temperament dimensions are buffered from the risk factors that may be associated with them. In this study we examine three dimensions of temperament, anger and fear tolerance, and attentional persistence as resilience factors that may contribute to adaptive versus maladaptive behavior in the context of contextual risk.

\section{Relational characteristics}

The study of early childhood behavior problems has focused on a number of indices of the parent-child relationship as predictors and risk factors in the emergence and maintenance of such problems. For example, a number of studies have shown that insecure infant attachment is predictive of later behavior problems in children (Booth, Rose-Krasnor, \& Rubin, 1991; Goldberg, Gotowiec, \& Simmons, 1995; Lyons-Ruth, Alpern, \& Repacholi, 1993; Renken, Egeland, Marvinney, Mangelsdorf, \& Sroufe, 1989; Shaw et al., 1998; Shaw, Owens, Vondra, Keenan, \& Winslow, 1996). In addition, a considerable body of evidence indicates that preschool children are more likely to show overactive, noncompliant, aggressive, and impulsive behavior when their parents are displaying negative control and are uninvolved, rejecting, and harsh (Campbell, 1995; Dumas \& LaFreniere, 1993; Hart, DeWolf, Wozniak, \& Burts, 1992; Pettit, Bates, \& Dodge, 1993). 
In addition to having insecure mother-child attachment histories and negative, controlling parents, children displaying child behavior problems have also been found to have less harmonious mother-child interactions (Gardner, $1987,1989,1994)$ and are low on affection, positive involvement, and warmth (McFadyenKetchum, Bates, Dodge, \& Pettit, 1996; Miller, Cowan, Cowan, Hetherington, \& Clingempeel, 1993). In other studies, mother-child relationships where the children are displaying behavior problems have been characterized by conflict and coercion. Patterson has identified a pattern of coercive interaction between mothers and children, where both the mothers' and children's aversive behaviors are reinforced and escalate as a result of this reinforcement (Patterson, 1982; Patterson, DeBaryshe, \& Ramsey, 1989). Finally, mothers of children displaying behavior problems have been found to be more adult focused by controlling and dominating activities with their children instead of being child focused and encouraging actions initiated by the children (Gardner, 1994; Rubin, Booth, Rose-Krasnor, \& Mills, 1995).

Thus, considerable evidence suggests that less conflict, more synchrony, and greater shared positive affect may be important elements of the child's relationship with the caregiver that may buffer the child from the negative effects of contextual risk factors. Such a parent-child dynamic may lead to declines in difficult behavior often characteristic of toddlerhood and to more harmonious parent-child interactions over time. Kochanska (1997) has conceptualized this aspect of the mother-child relationship as a mutually responsive orientation (MRO). She hypothesizes that when there is a greater MRO between a mother and child, maternal use of control and coercion should be decreased because the child is more receptive to parental goals (Maccoby, 1984). Such a dynamic also sets the stage for positive and successful socialization within the parent-child dyad, which results in fewer behavior problems and greater social competence (Deater-Deckard, Atzaba-Poria, \& Pike, 2004; Deater-Deckard \& Petrill, 2004; Kochanska, Forman, \& Coy, 1999; Kochanska \& Murray, 2000).

In sum, our multilevel approach to the role of resilience factors in the trajectories of early childhood behavior problems focuses on specific dimensions of biological, behavioral, and relational factors that are theoretically and empirically linked to early adjustment. Our speculation of the role these within child factors may play in such adjustment has emphasized main effects of these potential buffers operating under conditions of risk. However, given that these resilience factors are conceptualized in our approach as operating within the child, they are clearly not functionally independent of one another. However, despite the obvious practical limitations to such an empirical approach, clearly, a developmental psychopathology framework necessitates the conceptual integration of these factors as part of a dynamic process of growth and change across early development.

\section{The Current Investigation}

The goal of this longitudinal study was to examine patterns of growth and change in behavior problems across the preschool period in a large, diverse, community sample of children at varying levels of risk for such problems. Three broad questions were addressed. First, we examined the general pattern of change from age 2 to age 5 to replicate prior work noting the decline in behavior problems across this period (see review by Campbell, 2002). Second, we examined three levels of child resilience factors (physiological, behavioral, and relational) as predictors of the level of both externalizing and internalizing type behavior problems at kindergarten entry. Third, we examined three levels of child resilience factors as predictors of patterns of change in behavior problems over time. We examined the main effect of contextual risk, hypothesizing that a higher level of risk would predict less steep declines in behavior problems over time and higher levels of behavior problems at kindergarten entry. We hypothesized that this main effect of risk would be moderated by higher levels of physiological regulation, lower anger, and proneness to fear (for externalizing and internalizing); higher levels of behavioral persistence; and higher levels of mutual responsive orientation. In addition, and based on prior work, we examined the role of gender in 
predicting rates of change in behavior problems over time (e.g., Campbell, 1997, 2002); we expected that boys would show more stable and less declining patterns of behavior problems over time compared to girls.

\section{Method}

Participants

The current sample utilized data from three cohorts of children who are part of an ongoing longitudinal study. The goal for recruitment was to obtain a sample of children who were at risk for developing future externalizing behavior problems that was representative of the surrounding community in terms of race and SES. All cohorts were recruited through child daycare centers, the County Health Department, and the local Women, Infants, and Children Program. Potential participants for Cohorts 1 and 2 were recruited at 2 years of age (Cohort 1: 1994-1996 and Cohort 2: 20002001) and screened using the Child Behavior Checklist (CBCL 2/3; Achenbach, 1992) completed by the mother to oversample for externalizing behavior problems. Children were identified as being at risk for future externalizing behaviors if they received an externalizing $\mathrm{T}$ score of 60 or above. Efforts were made to obtain approximately equal numbers of males and females. A total of 307 children were selected.

Cohort 3 was initially recruited when infants were 6 months of age (in 1998) for their level of frustration based on laboratory observation and parent report, and were followed through the toddler period (see Calkins, Dedmon, Gill, Lomax, \& Johnson, 2002, for more information). Children whose mothers had completed the CBCL at 2 years of age were included in the current study $(\mathrm{n}=140)$. Of the entire sample $(\mathrm{N}=447), 37 \%$ of the children were identified as being at risk for future externalizing problems. There were no significant demographic differences between cohorts with regard to gender, $X^{2}(2, \mathrm{~N}=447)=.63, \mathrm{p}=$ .73 ; race, $X^{2}(2, \mathrm{~N}=447)=1.13, \mathrm{p}=.57$; or 2 -yearSES, $\mathrm{F}(2,444)=.53, \mathrm{p}=.59$. Cohort 3 had a significantly lower average 2-year externalizing $\mathrm{T}$ score $(\mathrm{M}=50.36)$ compared to
Cohorts 1 and $2(\mathrm{M}=54.49), \mathrm{t}(445)=4.32$,

$\mathrm{p}=.00$.

Of the 447 original screened participants, 6 were dropped because they did not participate in any 2-year data collection. At 4 years of age, 399 families participated. Families lost to attrition included those who could not be located, moved out of the area, declined participation, and did not respond to phone and letter requests to participate. There were no significant differences between families who did and did not participate in terms of gender, $X^{2}(1, \mathrm{~N}=$ $447)=3.27, \mathrm{p}=.07$; $\operatorname{race}, X^{2}(1, \mathrm{~N}=$ $447)=.70, \mathrm{p}=.40 ; 2$-year SES, $\mathrm{t}(424)=$ $.81, \mathrm{p}=.42$; or 2-year externalizing $\mathrm{T}$ score, $\mathrm{t}$ $(445)=.36, p=.72$. At 5 years of age 365 families participated including 4 that did not participate in the 4-year assessment. Again, there were no significant differences between families who did and did not participate in terms of gender, $X^{2}(1, \mathrm{~N}=447)=.76, \mathrm{p}=.38$; race, $X^{2}(1, \mathrm{~N}=447)=.17, \mathrm{p}=.68 ; 2$-year SES, $\mathrm{t}$ $(424=1.93, \mathrm{p}=.06)$; and 2-year externalizing

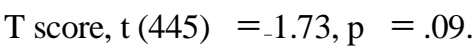

The current sample included 441 children (213 male, 228 female). Sixty-seven percent were European American, 27\% were African American, $4 \%$ were biracial, and $2 \%$ were Hispanic. At age 2, the children were primarily from intact families $(81 \%)$ and families were economically diverse based on Hollingshead (1975) SES scores $(\mathrm{M}=39.63, \mathrm{SD}=11.17)$.

Procedures

Children and their mothers participated in the study when the children were 2 , 4, and 5 years of age. During the laboratory assessments, the children and their mothers engaged in a series of tasks designed to elicit emotional and behavioral responding and mother-child interaction behaviors. Heart rate data was collected during some of the tasks. At the beginning of the laboratory assessment, an experimenter placed three disposable pediatric electrodes in an inverted triangle pattern on the child's chest. The electrodes were connected to a preamplifier and the output from the preamplifier was transmitted to a vagal tone monitor (VFM-I Delta Biometrics, Bethesda, MD) for R-wave detection. A data file containing the interbeat 
intervals (IBIs) for the entire period of heart rate collection were saved on a laptop computer for later artifact editing (e.g., resulting from child movement) and analysis. At each assessment, mothers also completed questionnaires assessing family demographics, their own functioning, and their child's behavior. The current study utilized data from the 2-year laboratory visit and maternal questionnaires from all three laboratory assessments.

\section{Measures}

Contextual risk. An index was created to assess the child's contextual risk at 2 years of age. Each of five individual indicators of risk were scored as present (1) or absent (0) and then summed to create a single contextual risk index. For continuous variables, individuals who scored within the lowest or highest quartile were placedin the risk category as indicated below.

SES. The Hollingshead Index (1975) was used to assess the family SES. Those scoring within the lowest quartile were considered to be at risk $(27 \%)$.

Marital status. Those who were unmarried were considered at risk (18.6\%).

Number of siblings. Risk was coded as present when families had more than two siblings when the child was 2 years of age $(21 \%)$.

Maternal psychopathology. The Symptom Checklist-90-Revised (Derogatis, 1986) was used to assess self-reported maternal psychopathology symptoms at the 2-year visit. The 90 items were rated on how much distress they caused over the previous 7 days using a 5-point scale ranging from 0 to 4 (not at all, a little bit, moderately, quite a bit, and extremely). Individual's with $\mathrm{T}$ scores 60 and above on the General Severity Index were assigned to the risk category (29\%).

Parenting stress. The Parenting Stress Index-Short Form (Abidin, 1995) was used to assess the source and degree of parenting stress when the child was 2 years of age. The index contains a total score as well as subscales for stress stemming from the child, the parent-child relationship, and the parent. Items were rated on a 5-point scale ranging from 1 to 5 (strongly agree, agree, not sure, disagree, and strongly disagree). The measure has good reliability and validity, with coefficients exceeding .80 (Abidin, 1995). Those scoring 90 and above on the total stress $\mathrm{T}$ score were assigned to the risk category (25\%).

On the basis of the Contextual Risk Index, $34 \%$ of the children had no risk factors, $32 \%$ had one risk factor, $21 \%$ had two risk factors, $7 \%$ had three risk factors, $5 \%$ had four risk factors, and $1 \%$ had five risk factors.

\section{Child resilience factors.}

Biological characteristics-Cardiac vagal regulation. Measures of children's baseline RSA and change in RSA from baseline during a positive task at age 2 were obtained by editing IBI flies using MXEDIF software (Delta Biometrics). To edit the files, the data were scanned for outlier points, relative to adjacent data, and the outliers were replaced by dividing or summing them so they would be consistent with the surrounding data. Only data files in which less than $10 \%$ of the data required editing were included in the current study. The Porges (1985) method of analyZing IBI data was used to calculate RSA. This method applies an algorithm to the sequential heart period (HP) data. The algorithm uses a moving 21-point polynomial to detrend periodicities in HP that are slower than RSA. Next, a bandpass filter extracts variance in HP within the frequency band of spontaneous respiration in young children $(0.24-1.04 \mathrm{~Hz})$. The natural logarithm (ln) of this variance is taken and reported in units of $\ln$ (milliseconds) $)^{2}$. RSA was calculated every $30 \mathrm{~s}$ for the baseline and bubble tasks and the average across the 30-s epochs for each episode was used in subsequent analyses. Data were excluded if the standard deviation for an episode was over 1.0.

Baseline RSA. This was obtained at the beginning of the laboratory visit while the child 
watched a 5-min segment of the videotape "Spot," a story about a puppy that explores its neighborhood. The use of the video stimulus was necessary to limit movement artifact in the data, given that the children were 2 years of age. Although this episode is not a true baseline, because the child's attention was engaged, it was sufficient to gain a measure of RSA while the child was sitting quietly and showing little affect. Children also participated in a bubble task that was designed to elicit focused attention and positive affect during which they were instructed on how to blow and pop bubbles. Children's change in RSA ( $\triangle \mathrm{RSA}$ ) was calculated by subtracting the RSA during the bubble task from the RSA during the baseline episode. Positive change scores occurred when there was a decrease from baseline to the bubble episode, which reflected attempts at vagal regulation. Negative change scores occurred when there was an increase from baseline to the bubble episode and reflected a state that does not require regulation.

Behavioral characteristics-Temperament The Toddler Behavior Assessment Questionnaire (Goldsmith, 1996) is a 108-item scale that was used to assess maternal reported temperament-related behavior at the 2-year visit. Items were rated on a 7-point scale (never, very rarely, less than half the time, about half the time, more than half the time, almost always, always). The measure includes five subscales that assess activity level, anger, fear, pleasure, and interest/persistence. The anger, social fear, and interest/persistence, subscales were utilized in the current study. Anger and fear were recoded so that higher scores indicate the child's level frustration tolerance and fearlessness. For persistence, higher scores indicate greater persistence.

Relationship characteristics - MRO. Parenting and child behaviors, across the different mother-child interaction tasks when the children were 2 years of age, were scored using global codes adapted from the Early Parenting Coding System (Winslow, Shaw, Bruns, \& Kiebler, 1995). Behaviors, which were coded during a puzzle task, free play, and clean-up task, received codes for warmth/positive affect (displaying positive affect and warmth toward the child) and sensitivity/responsiveness (promptly and appropriately responding to the child's bids to her). Behaviors were coded on a 4-point scale ranging from low to high (none, a little, some, a lot). Reliability was calculated on all tasks for $10 \%$ of the total sample that two research assistants coded together and another $10 \%$ that were coded separately. Adjusted kappa values were all above .70 . Proportion scores were created that reflected the percentage of tasks in which both the mother and child expressed high levels of mutual responsiveness and mutual positive affect. Specifically, the relationship was coded as mutual when both the mother and child expressed high levels of each behavior (i.e., both were coded as a lot). The mutual responsiveness and mutual positive affect proportion scores were summed to create an index of MRO. Higher scores indicate greater levels of mutually responsive behavior.

Behavior problems. The CBCL was used to assess both externalizing and internalizing behaviors (Achenbach \& Edelbrock, 1983). Mothers completed the CBCL for 2- to 3-year-olds when the children were 2 years of age (Achenbach, 1992) and the CBCL for 4- to 18-year-olds when the children were 4 and 5 years of age (Achenbach, 1991). These scales have been found to be a reliable index of externalizing and internalizing behavior problems across childhood (Achenbach, 1992; Achenbach, Edelbrock, \& Howell, 1987). At 2 years of age, the externalizing subscale consisted of 26 items that included the minor subscales of aggression and destructive behavior. The internalizing subscale consisted of 25 items that included the minor subscales of anxious/depressed and withdrawn. At 4 and 5 years of age, the externalizing subscale consisted of 33 items that included the minor subscales of aggression and delinquency. The internalizing subscale consisted of 32 items that included the minor subscales of anxious/depressed, withdrawn, and somatic complaints. Mothers rated their child on a 3-point scale (not true, sometimes true, often true). Because different versions of this measure were completed because of the child's age at the time of assessment and because we 
were interested in the children's behaviors relative to the respective level of behaviors given children's respective ages, the CBCL externalizing and internalizing $\mathrm{T}$ scores were used. Higher scores indicated higher levels of externalizing and internalizing behaviors.

\section{Data analytic strategy}

Growth curve analyses were conducted to examine the developmental trajectories of externalizing and internalizing behavior problems in early childhood, using hierarchical linear modeling (HLM; Raudenbush \& Byrk, 2002). HLM was used because it allows for unbalanced designs so those children with incomplete outcome data across the three waves could be included in the analyses. For the current study, externalizing and internalizing behavior problems were assessed when children were 2, 4 , and 5 years of age. Linear growth trajectories were fit using full maximum likelihood estimation and the results reported are based on the robust standard errors. Linear models have been recognized as providing a good approximation about the nature of change that occurs even when the actual change is more complex (Rogosa, Brant, \& zimowski, 1982). Age was centered at 5 years so that the intercept indicated the status at the end of the growth period examined and the coefficients indicate the change that occurred in 1-year increments starting at

age 2. Gender was effect coded (male $=-1$,

female $=1$ ) and all continuous variables were mean centered. Initially, unconditional growth models were fitted to explore developmental trajectories of externalizing and internalizing behavior problems across early childhood. Next, we fitted an explanatory model to characterize how well changes in children's externalizing and internalizing behaviors were predicted by contextual risk as well as three levels of resilience factors: biological, behavioral, and relational. The interaction terms between contextual risk and the resilience factors were included to examine whether the link between vagal regulation, child temperament, and motherchild relationship quality and children's behavior problems was moderated by the child's level of contextual risk. Significant interactions were plotted so that high risk represents an individual with a risk index score of 3 and low risk represents an individual with a risk index score of one (Aiken \& West, 1991). All other continuous variables were plotted at \pm 1 $\mathrm{SD}$ from the mean.

\section{Results}

The results are organized as follows. First, analyses are conducted to assess the pattern of missing data. Second, preliminary analyses including descriptive statistics and intercorrelations for all study variables are presented. Third, the results from the HLM models are reported.

\section{Missing data}

The use of HLM accounts for missing data longitudinally under the assumption that the data are missing at random (MAR). Thus, despite attrition between 2 and 5 years of age, the analysis included all 441 participants. Overall patterns of missing data were examined revealing that missing data were predicted by the continuous 2-year variables included in

the model, Little's MCAR text, $\mathrm{x}^{2}(831)=$ 911.21, $\mathrm{p}<.05$, indicating that the data was MAR.

HLM does not allow for missing data within the time invariant (Level 2) predictor variables; therefore, data were imputed for Level 2 predictor variables. Listwise deletion of cases without complete data would have resulted in an over $49 \%$ reduction in sample size that would have produced a significant loss in power and possible bias. The amount of missing data for any one variable was relatively small: maternal depression (19\%), maternal psychopathology (11\%), child temperament variables $(21 \%)$,

baseline RSA (21\%), $\Delta \Delta_{\text {RSA baseline }}-$ positive task (28\%), and MRO (3\%). Missing values were imputed through maximum likelihood estimation using the expectation maximization method (EM) algorithm in SPSS 13. The EM method is an iterative process to impute missingvalues that has been found to be superior to listwise deletion, mean substitution, and multiple regression (Garson, 2006). All the analyses presented are based on the imputed Level 2 data. 
Preliminary analyses

Descriptive statistics for all study variables are presented in Table 1. Intercorrelations among study variables indicate that contextual risk was associated with child temperament, MRO, and both externalizing and internalizing behavior problems (Table 2).

Early developmental trajectories of externalizing and internalizing behavior problems

Unconditional growth models were fit to explore the developmental trajectories of children's externalizing and internalizing behavior problems from 2 to 5 years of age (Table 3 ). The fixed effects indicated that from 2 to 5 years of age children's externalizing behavior problems $\mathrm{T}$ score decreased by .41 points each year. At 5 years of age, the average externalizing behavior problems score was 51.91. Internalizing behavior $\mathrm{T}$ scores also decreased from 2 to 5 years of age at a rate of .74 points each year. At 5 years of age, the average estimated internalizing behavior score was
46.37. For both externalizing (intercept $=.78$, slope $=.46$ ) and internalizing (intercept $=.69$, slope $=.44$ ) behavior problems, the parameter estimates had adequate reliability.

The variances around the intercept and slope (random effects) indicate whether the parameter estimates vary across children and represent individual differences in the linear change that occurs from 2 to 5 years of age and overall levels of behavior at age 5. For both externalizing and internalizing behavior problems, the random effects were significant (Table 3 ). This indicates that there is substantial interindividual heterogeneity that can be explained by including predictors in the model.

\section{Risk and resilience as predictors of externalizing and internalizing behavior problem trajectories}

Next we examined how contextual risk, vagal regulation, child temperament, and a MRO between the mother and child assessed when children were 2 years of age predicted both the rate of change in externalizing and internalizing

Table 1. Descriptive statistics for predictor and outcome measures

\begin{tabular}{lcccr}
\hline \multicolumn{1}{c}{ Measures } & $n$ & $M$ & $S D$ & \multicolumn{1}{c}{ Range } \\
\hline & 2-Year Measures & & \\
\hline Contextual risk & 441 & 1.21 & 1.19 & $0.00-5.00$ \\
Baseline RSA & 441 & 5.43 & 1.16 & $1.10-8.79$ \\
$\Delta$ RSA (baseline - positive) & 441 & 0.46 & 0.67 & $-2.14-3.22$ \\
Frustration tolerance & 441 & 4.09 & 0.81 & $1.67-6.43$ \\
Persistence & 441 & 4.44 & 0.66 & $1.75-6.14$ \\
Fearlessness & 441 & 4.23 & 0.88 & $1.31-6.79$ \\
Mutually responsive orientation & 441 & 0.87 & 0.72 & $0.00-2.00$ \\
Externalizing problems & 441 & 53.15 & 9.82 & $30.00-91.00$ \\
Internalizing problems & 441 & 48.92 & 9.93 & $30.00-90.00$ \\
& & & & \\
\hline & $4-Y e a r$ Measures & & \\
\hline Externalizing problems & 375 & 52.26 & 9.36 & $30.00-76.00$ \\
Internalizing problems & 375 & 45.88 & 9.09 & $33.00-73.00$ \\
\hline & & & & \\
\hline Externalizing problems & 343 & 51.72 & 10.26 & $30.00-79.00$ \\
Internalizing problems & 343 & 47.31 & 9.80 & $33.00-82.00$ \\
\hline \hline
\end{tabular}

Note: RSA, respiratory sinus arrhythmia. 
Table 2. Intercorrelations for study variables

\begin{tabular}{|c|c|c|c|c|c|c|c|c|c|c|c|c|}
\hline Variables & 1 & 2 & 3 & 4 & 5 & 6 & 7 & 8 & 9 & 10 & 11 & 12 \\
\hline \multicolumn{13}{|c|}{ Predictor Variables } \\
\hline \multicolumn{13}{|l|}{ 1. Risk Index } \\
\hline 2. Baseline RSA & .04 & & & & & & & & & & & \\
\hline 3. $\triangle \mathrm{RSA}$ (baseline - positive) & -.02 & $.44 * * *$ & & & & & & & & & & \\
\hline 4. Frustration tolerance & $-.28 * * *$ & $-.11 *$ & .01 & & & & & & & & & \\
\hline 5. Persistence & $-.19 * * *$ & .03 & $.11 *$ & $.27 * * *$ & & & & & & & & \\
\hline 6. Fearlessness & $-.13 * * *$ & .05 & -.07 & $.27 * * *$ & $.13^{*}$ & & & & & & & \\
\hline 7. Mutually responsive orientation & $-.25 * * *$ & $-.13 * *$ & -.06 & $.21 * * *$ & .02 & .05 & & & & & & \\
\hline \multicolumn{13}{|c|}{ Outcome Variables } \\
\hline 8. Externalizing's 2 year & $.35 * * *$ & .03 & -.03 & $-.54 * * *$ & $-.27 * * *$ & .06 & $-.13 * *$ & & & & & \\
\hline 9. Internalizing's 2 year & $.39 * * *$ & -.02 & $-.08 \dagger$ & $-.44 * * *$ & $-.27 * * *$ & $-.32 * * *$ & $-.11^{*}$ & $.78 * * *$ & & & & \\
\hline 10. Externalizing's 4 year & $.28 * * *$ & .01 & $-.09 \dagger$ & $-.40 * * *$ & $-.27 * * *$ & .02 & -.04 & $.61 * * *$ & $.48 * * *$ & & & \\
\hline 11. Internalizing's 4 year & $.27 * * *$ & $.13^{* * *}$ & -.01 & $-.23 * * *$ & $-.13^{*}$ & $-.14 * *$ & .01 & $.38 * * *$ & $.45^{* * *}$ & $.60 * * *$ & & \\
\hline 12. Externalizing's 5 year & $.25 * * *$ & $.10 \dagger$ & $-.12 *$ & $-.36 * * *$ & $-.21 * * *$ & .06 & -.03 & $.39 * * *$ & $.74 * * *$ & $.74 * * *$ & $.49 * * *$ & \\
\hline 13. Internalizing's 5 year & $.24 * * *$ & .07 & -.05 & $-.23 * * *$ & $-.16^{*}$ & $-.10 \dagger$ & .04 & $.55^{* * * *}$ & $.40^{* * *}$ & $.50 * * *$ & $.66 * * *$ & $.61 * * *$ \\
\hline
\end{tabular}

Note: RSA, respiratory sinus arrhythmia.

$\dagger p<.10 .{ }^{*} p<.05 . * * p<.01 . *^{* * *} p<.001$ 
Table 3. Unconditional growth models for externalizing and internalizing behavior problems

\begin{tabular}{|c|c|c|c|c|c|c|}
\hline \multirow[b]{2}{*}{ Fixed Effects } & \multicolumn{3}{|c|}{ Externalizing } & \multicolumn{3}{|c|}{ Internalizing } \\
\hline & Coefficient ${ }^{a}$ & $S E$ & $t$ & Coefficient ${ }^{a}$ & $S E$ & $t$ \\
\hline Intercept (5 year) & 51.91 & 0.49 & $105.16^{* * *}$ & 46.37 & 0.49 & $95.12^{* * *}$ \\
\hline Slope & -0.41 & 0.16 & $-2.50^{*}$ & -0.74 & 0.19 & $-3.95^{* * *}$ \\
\hline Random Effects & $\begin{array}{l}\text { Variance } \\
\text { Component }\end{array}$ & $d f$ & $x^{2}$ & $\begin{array}{l}\text { Variance } \\
\text { Component }\end{array}$ & $d f$ & $\chi^{2}$ \\
\hline Intercept (5 year) & 8.76 & 391 & $1956.61 * * *$ & 8.09 & 391 & $1353.23 * * *$ \\
\hline Slope & 2.23 & 391 & $725.66 * * *$ & 6.29 & 391 & $712.08 * * *$ \\
\hline
\end{tabular}

${ }^{a}$ Coefficients indicate the change that occurred in 1-year increments starting at age 2 .

$* p<.05$. *** $p<.001$

behavior over time and children's level of behavior problems when they were 5 years of age. These explanatory models included all the variables of interest including the risk interaction terms as predictors of both the intercept and slope.

Results for externalizing behavior problems are displayed in Table 4. The fixed effects indicate that greater behavior problems at Year 5 (intercept) were predicted by higher contextual risk, greater baseline RSA, higher levels of fearlessness, greater MRO between the mother and child, smaller change in RSA, lower frustration tolerance, and lower persistence. There was also a significant Risk $x$ MRO interaction (Figure 1), indicating that for those children who were at greater risk at 2 years of age, higher MRO at 2 years was related to higher externalizing behavior problems at 5 years.

For the change in externalizing behavior problems from 2 to 5 years of age we found that boys declined at a faster rate than girls who tended to stay stable over time. In addition, having lower baseline RSA, greater change in RSA and lower levels of frustration tolerance was also linked with greater declines in externalizing behavior problems. It should be noted, however, that children with higher frustration tolerance had overall lower levels of externalizing behavior problems than those with lower levels of frustration tolerance. None of the risk interaction terms included in the model were significant.

The overall proportion of variance accounted for in the explanatory model was calculated relative to the variance in the unconditional growth model (i.e., variance unconditional growth model - variance explanatory model/variance unconditional growth model; Singer \& Willett, 2003). The relative proportion of variance explained was $29 \%$ for the intercept and $18 \%$ for the slope.

Results for internalizing behavior problems are displayed in Table 5. The fixed effects indicate that greater internalizing behavior problems at Year 5 (intercept) were predicted by higher contextual risk, greater baseline RSA, a more MRO between the mother and child, and lower frustration tolerance. There were two significant interactions predicting the intercept. For children who were at greater risk at 2 years of age, a more MRO between mother and child was related to higher internalizing problems at 5 years of age (Figure 2). In addition, for children who were at greater risk at 2 years of age, lower persistence was related to higher internalizing problems at 5 years (Figure 3).

Declines in internalizing behavior problems from 2 to 5 years of age were associated with lower baseline RSA and lower levels of frustration tolerance, although higher frustration tolerance actually had lower levels of internalizing behavior problems across early childhood. Greater fearlessness was associated with a steeper decline in internalizing behavior problems over time, but this association was moderated by risk. The three-way interaction among Risk $\mathrm{x}$ Fearlessness $\mathrm{x}$ Time is depicted in Figure 4. 
Table 4. Externalizing behavior problems trajectories

\begin{tabular}{|c|c|c|c|}
\hline Fixed Effects & Coefficient $^{a}$ & $S E$ & $t$ \\
\hline Intercept & 54.97 & 0.47 & $109.67^{* * *}$ \\
\hline Female & 0.51 & 0.44 & 1.16 \\
\hline Risk & 1.68 & 0.44 & $3.83 * * *$ \\
\hline Baseline RSA & 0.87 & 0.43 & $2.03^{*}$ \\
\hline$\Delta$ RSA (baseline - positive task) & -2.04 & 0.74 & $-2.77 * *$ \\
\hline Frustration tolerance & -3.65 & 0.60 & $-6.08 * * *$ \\
\hline Persistence & -1.89 & 0.69 & $-2.75^{* *}$ \\
\hline Fearlessness & 1.83 & 0.52 & $3.50 * *$ \\
\hline Mutually responsive orientation & 1.44 & 0.65 & $2.21^{*}$ \\
\hline Risk $\times$ Baseline RSA & 0.02 & 0.34 & 0.07 \\
\hline Risk $\times \Delta$ RSA & -0.13 & 0.65 & -0.20 \\
\hline Risk $\times$ Frustration Tolerance & -0.54 & 0.49 & -1.10 \\
\hline Risk $\times$ Persistence & -0.63 & 0.67 & -0.94 \\
\hline Risk $\times$ Fearlessness & -0.09 & 0.45 & -0.20 \\
\hline Risk $\times$ Mutually Responsive Orientation & 1.27 & 0.58 & $2.19 *$ \\
\hline Slope & -0.40 & 0.17 & $-2.36^{*}$ \\
\hline Female & 0.38 & 0.16 & $2.40^{*}$ \\
\hline Risk & -0.08 & 0.16 & -0.51 \\
\hline Baseline RSA & 0.40 & 0.15 & $2.58^{*}$ \\
\hline$\Delta$ RSA (baseline - positive task) & -0.72 & 0.26 & $-2.72 * *$ \\
\hline Frustration tolerance & 0.65 & 0.22 & $2.99 * *$ \\
\hline Persistence & -0.07 & 0.25 & -0.27 \\
\hline Fearlessness & 0.25 & 0.19 & 1.32 \\
\hline Mutually responsive orientation & 0.32 & 0.23 & 1.37 \\
\hline Risk $\times$ Baseline RSA & -0.05 & 0.12 & -0.39 \\
\hline Risk $\times \Delta$ RSA & 0.04 & 0.23 & 0.16 \\
\hline Risk $\times$ Frustration Tolerance & 0.03 & 0.18 & 0.14 \\
\hline Risk $\times$ Persistence & -0.25 & 0.24 & -1.05 \\
\hline Risk $\times$ Fearlessness & 0.01 & 0.16 & 0.08 \\
\hline \multirow[t]{2}{*}{ Risk $\times$ Mutually Responsive Orientation } & 0.12 & 0.21 & 0.59 \\
\hline & $\begin{array}{l}\text { Variance } \\
\text { Component }\end{array}$ & $d f$ & $x^{2}$ \\
\hline Intercept & 54.47 & 377 & $1488.43 * * *$ \\
\hline Slope & 4.08 & 377 & $665.77 * * *$ \\
\hline
\end{tabular}

Note: RSA, respiratory sinus arrhythmia.

${ }^{a}$ Coefficients indicate the change that occurred in 1-year increments starting at age 2 .

${ }^{*} p<.05 .{ }^{* *} p<.01 .{ }^{* * *} p<.001$.

Specifically, children who had high contextual risk and were high on fearlessness had the highest level of internalizing behavior problems even though they decreased over time. Children who had low fearlessness had overall lower levels of internalizing behavior problems and they decreased similarly. For children with low contextual risk, however, there were differences in their change over time based on their fearlessness. Internalizing problems decreased when children were low on fearlessness, but stayed stable with the lowest level of internalizing behavior problems if they were high on fearlessness. In summary, children's temperamental fearlessness has differential influences on children's internalizing behavior problems under conditions of low and high contextual risk.

Greater declines in internalizing behavior problems were also linked with a less MRO between the mother and child. This was also moderated by risk, as there was a significant Risk x MRO x Time interaction (Figure 5). Specifically, under conditions of high contextual risk children who experienced a more MRO with their mother had the greatest level of 


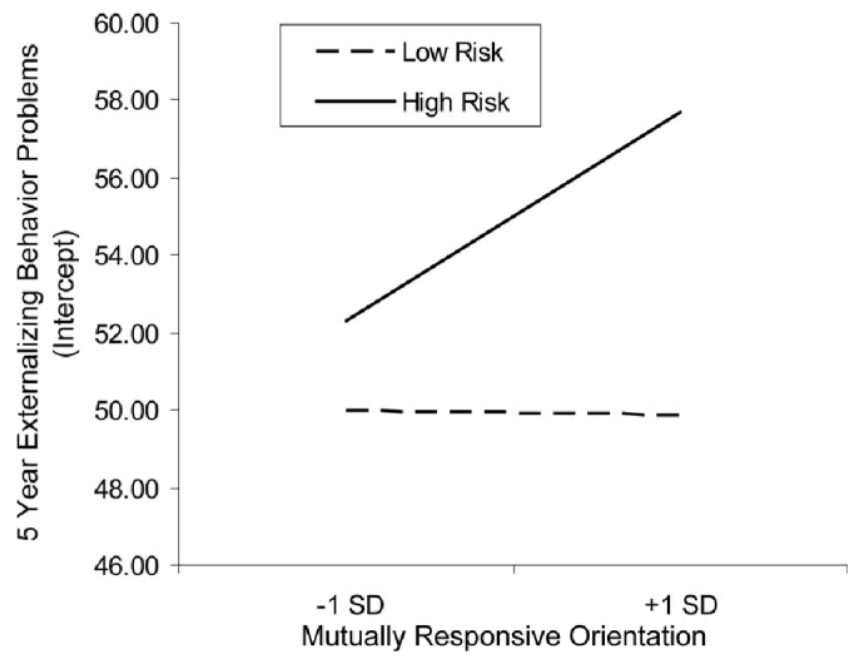

Figure 1. The interaction between contextual risk and mutually responsive orientation between the mother and child predicting 5-year externalizing behavior problems.

internalizing behavior problems and they increased slightly over time. Under conditions of high risk but with a less mutually responsive relationship with their mother, children were initially higher on internalizing behavior problems but they decreased over time. For internalizing behavior problems, the relative proportion of variance explained was $22 \%$ for the intercept and $27 \%$ for the slope.

Finally, the random effects from the explanatory models indicate that for both externalizing and internalizing behavior problems there was still significant variation in the intercept and slope that was not accounted for by the predictors included in the model.

\section{Discussion}

The goal of the present study was to examine growth and change across the preschool years in externalizing and internalizing behavior problems in a large community sample of children. Given that such problems become more intransigent and difficult to treat as children develop, the early identification of these problems and the risk and protective factors associated with them is a significant goal for basic scientists and practitioners alike. We adopted developmental psychopathology as our conceptual framework. This perspective invites consideration of the multiple processes and pathways in early development and aims to identify risk and protective factors that clarify the various conditions under which child functioning is compromised.

Our work with community samples lends itself to an examination of contextual risk factors-those features of the child's social and economic environment that make successful adaptation more challenging, although not necessarily unlikely. We identified five common indicators of contextual risk and, following Sameroff and others (Rutter, 1987; Sameroff et al., 2003), created a composite of risk that we predicted would be associated with poorer functioning as indicated by higher scores on the CBCL subscales and less steep declines in such problems across preschool. Specifically, we modeled trajectories of children's behavior problems from 2 to 5 years of age as a function of both risk and three levels of child resilience where the intercept was coded to predict children's level of behavior problems at the end of the developmental period examined. Our expectation was that risk would be moderated by several within child resilience factors that have been linked in prior research with better versus worse competence among young children. Such an approach is consistent with a conceptual framework that views development as a dynamic process that may be observed across multiple interacting levels of analysis. 
Table 5. Internalizing behavior problems trajectories

\begin{tabular}{|c|c|c|c|}
\hline Fixed Effects & Coefficient $^{a}$ & $S E$ & $t$ \\
\hline Intercept & 46.61 & 0.51 & $92.11 * * *$ \\
\hline Female & -0.35 & 0.47 & -0.74 \\
\hline Risk & 2.21 & 0.43 & $5.20 * * *$ \\
\hline Baseline RSA & 0.99 & 0.48 & $2.06^{*}$ \\
\hline$\Delta$ RSA (baseline - positive task) & -1.06 & 0.78 & -1.36 \\
\hline Frustration tolerance & -1.12 & 0.57 & $-1.96 *$ \\
\hline Persistence & -0.63 & 0.64 & -0.97 \\
\hline Fearlessness & -0.62 & 0.56 & -1.12 \\
\hline Mutually responsive orientation & 2.29 & 0.63 & $3.62 * *$ \\
\hline Risk $\times$ Baseline RSA & 0.16 & 0.34 & 0.47 \\
\hline Risk $\times \Delta$ RSA & 0.29 & 0.67 & 0.44 \\
\hline Risk $\times$ Frustration Tolerance & -0.71 & 0.45 & -1.58 \\
\hline Risk $\times$ Persistence & -0.99 & 0.58 & $-1.71 \dagger$ \\
\hline Risk $\times$ Fearlessness & -0.44 & 0.38 & -1.14 \\
\hline Risk $\times$ Mutually Responsive Orientation & 2.34 & 0.55 & $4.25^{* * *}$ \\
\hline Slope & -0.68 & 0.19 & $-3.61 * *$ \\
\hline Female & 0.05 & 0.18 & 0.29 \\
\hline Risk & -0.09 & 0.16 & -0.55 \\
\hline Baseline RSA & 0.41 & 0.17 & $2.45^{*}$ \\
\hline$\Delta$ RSA (baseline - positive task) & -0.05 & 0.31 & -0.18 \\
\hline Frustration tolerance & 0.66 & 0.23 & $2.85^{* *}$ \\
\hline Persistence & 0.31 & 0.26 & 1.18 \\
\hline Fearlessness & 0.57 & 0.22 & $2.63^{* *}$ \\
\hline Mutually responsive orientation & 0.63 & 0.25 & $2.50^{*}$ \\
\hline Risk $\times$ Baseline RSA & -0.07 & 0.14 & -0.51 \\
\hline Risk $\times \Delta$ RSA & 0.34 & 0.27 & 1.28 \\
\hline Risk $\times$ Frustration Tolerance & -0.12 & 0.18 & -0.63 \\
\hline Risk $\times$ Persistence & -0.27 & 0.24 & -1.13 \\
\hline Risk $\times$ Fearlessness & -0.28 & 0.16 & $-1.77^{\dagger}$ \\
\hline \multirow[t]{2}{*}{ Risk $\times$ Mutually Responsive Orientation } & 0.50 & 0.21 & $2.36^{*}$ \\
\hline & $\begin{array}{l}\text { Variance } \\
\text { Component }\end{array}$ & $d f$ & $\chi^{2}$ \\
\hline Intercept & 51.07 & 377 & $1141.38 * * *$ \\
\hline Slope & 4.61 & 377 & $634.59 * * *$ \\
\hline
\end{tabular}

Note: RSA, respiratory sinus arrhythmia.

${ }^{a}$ Coefficients indicate the change that occurred in 1 -year increments starting at age 2 .

$\dagger p<.10 .{ }^{*} p<.05 .{ }^{* *} p<.01 .{ }^{* * *} p<.001$.

The first aim of the study was to examine the trajectories of both subtypes of behavior problems to observe whether the expected pattern of decline across time that has been found in the literature would be revealed (Hartup, 1974; Tremblay, 2000). In general, both externalizing and internalizing behavior problems did decrease over time, although there was substantial interindividual heterogeneity. Given these individual differences in children's trajectories of externalizing and internalizing behavior problems, we fit a model that included risk, as well as three levels of child resilience that were anticipated to moderate risk, including biological, behavioral, and relational characteristics. Overall, different patterns of findings emerged for the two subtypes of behavior problems, with multiple resilience factors clearly playing a role in the prediction of the change that occurred across early childhood in problem behavior and their level of behavior problems when they reached kindergarten age. The fIndings lend support to the developmental psychopathology perspective that views development 


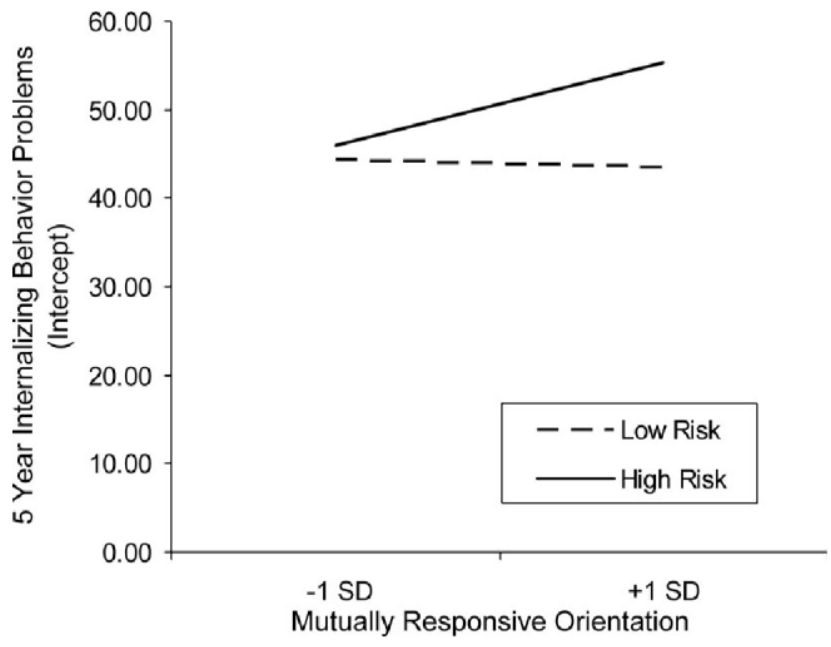

Figure 2. The interaction between contextual risk and mutually responsive orientation between the mother and child predicting 5-year internalizing behavior problems.

as a process characterized by multiple possible pathways to adaptation and maladaptation, in this case, in the form of either externalizing or internalizing problems.

Risk and resilience as predictors of the level and trajectories of externalizing behavior problems

Our analysis of externalizing behavior problems revealed that higher levels of such problems at age 5 were predicted by a number of factors.
As expected, the level of risk at 2 years of age significantly predicted the level of externalizing behavior problems. This confirms numerous prior studies in which contextual risk associated with lower social and economic resources, poorer parent functioning, and more competition for resources and parent interaction (by virtue of more siblings) challenges the family system, and thus the child, to engage in adaptive behavior.

In addition, a number of interesting effects were observed in our analysis of the three resilience

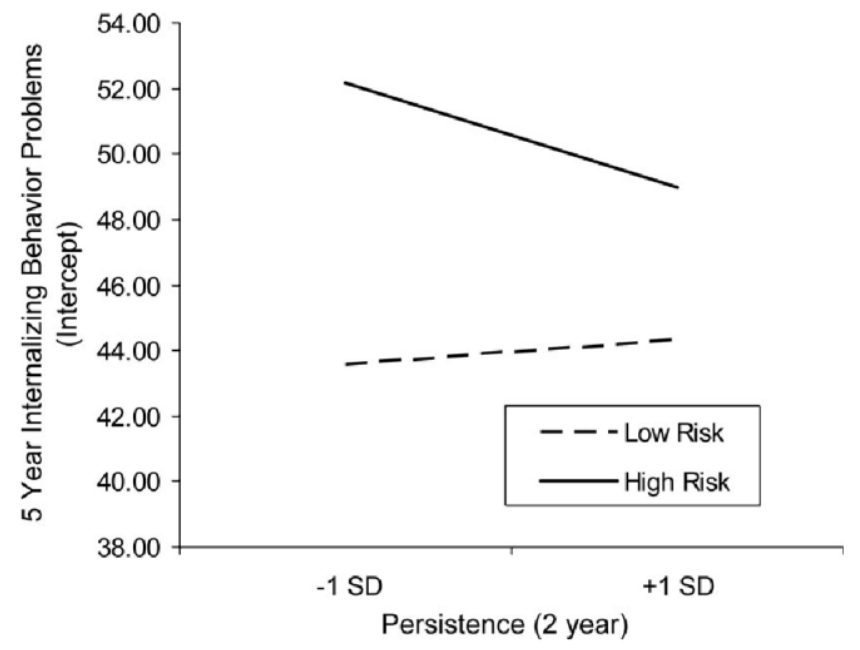

Figure 3. The interaction between contextual risk and child persistence predicting 5-year intemalizing behavior problems. 


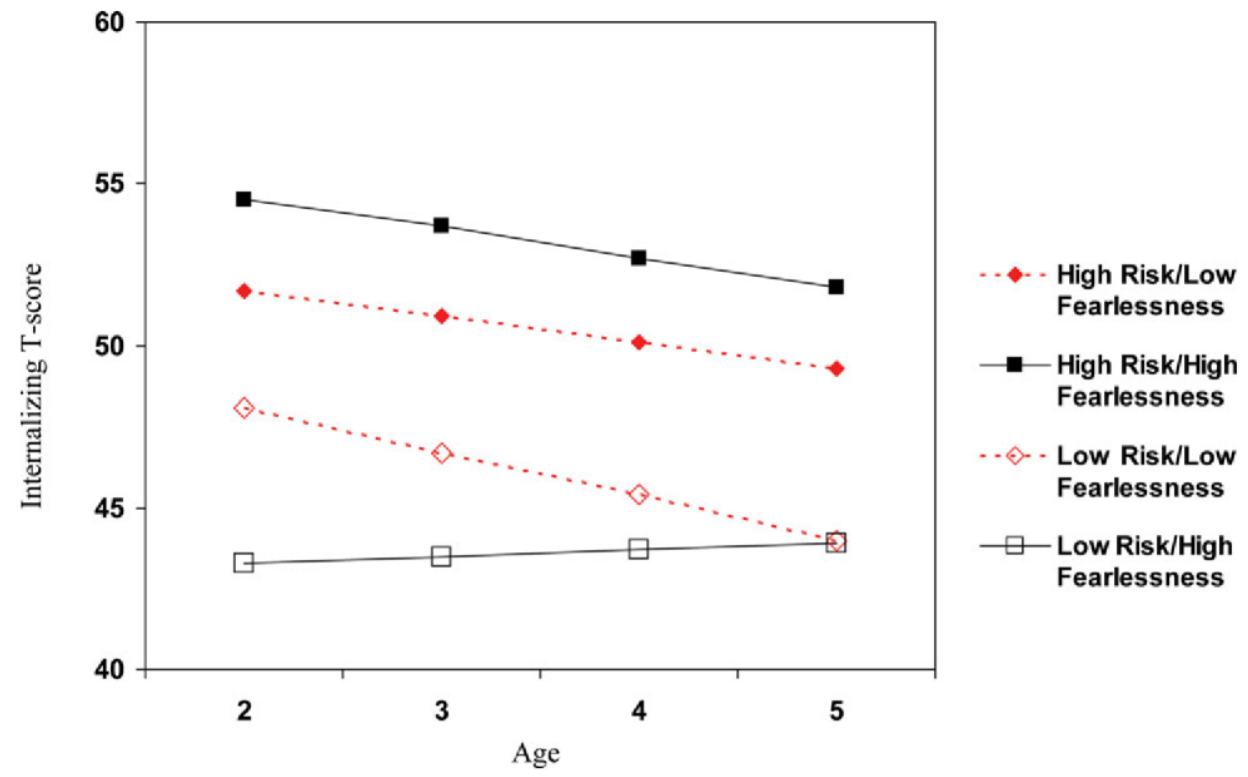

Figure 4. The interaction of contextual risk, fearlessness, and time predicting change in internalizing behavior problems from 2 to 5 years of age. [A color version of this figure can be viewed online at www.journals. cambridge.org]

factors thought to offset these contextual challenges. Both biological and behavioral resilience factors played a role in the rate of behavior at age 5 and in the decline of externalizing prob- lems over time. Children who exhibited greater physiological regulation, in the form of greater decline of RSA in response to an attentional/ emotional challenge, greater frustration toler-

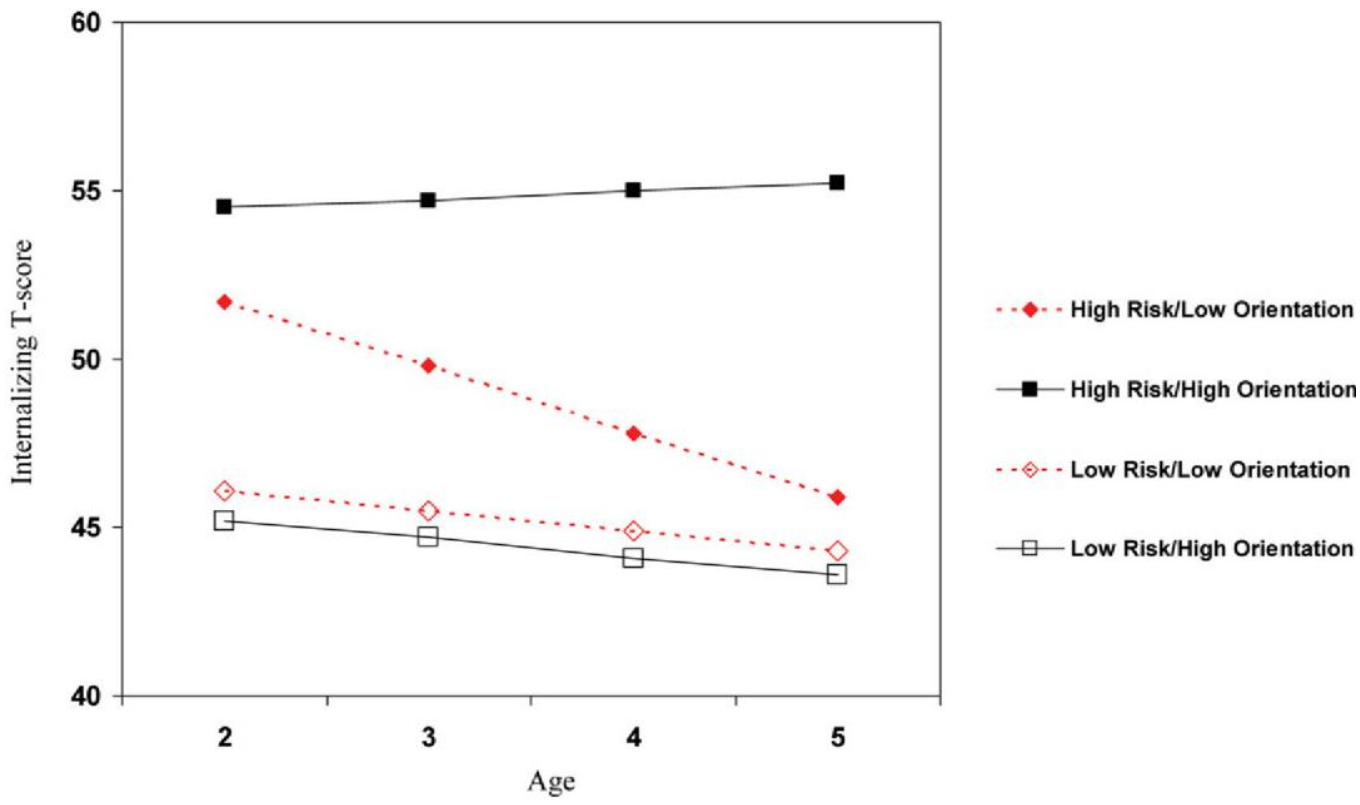

Figure 5. The interaction of contextual risk, mutually responsive orientation, and time predicting change in internalizing behavior problems from 2 to 5 years of age. [A color version of this figure can be viewed online at www.journals.cambridge.org] 
ance, and higher persistence, evidenced lower levels of externalizing type behaviors at age five, regardless of risk status. It is likely that each of these within child factors operates by facilitating the regulation of affect that is often a challenge for children with behavior problems (Calkins \& Dedmon, 2000). In addition, and consistent with the previous literature, we found that children with higher levels of baseline RSA and greater fear tolerance (fearlessness) engaged in more externalizing behaviors when they were 5 years of age. Basal RSA is often considered an indicator of emotional reactivity (Calkins, 1997). To the degree that some children are reactive, but fail to develop regulatory strategies to control that reactivity, problem behavior may be more likely (Calkins, Smith, Gill, \& Johnson, 1998). Given that among older children, low levels of fear have been associated with greater conduct problems (Shaw, Gilliom, Ingoldsby, \& Nagin, 2003), it is not surprising that a similar pattern of results has emerged with younger children.

In examining the change in externalizing behavior problems from 2 to 5 years of age we found that boys declined at a faster rate than girls who overall had lower levels of behavior problems that tended to stay stable over time. This may be partially attributable to the fact that we oversampled for externalizing behavior problems, which for girls may have attenuated the normative declines in behavior problems that are generally found. Indeed, in the current sample, there were no mean differences at each wave in externalizing behavior problems between boys and girls. In addition, children who had lower baseline RSA, greater vagal regulation and lower levels of frustration tolerance also had greater declines in externalizing behavior problems. Contextual risk, however, was not associated with the change that occurred in externalizing behavior problems over time.

In our analysis of the effects of relational resilience, we found that a more MRO between 2 -year-old children and their mothers was linked to greater levels of externalizing when children were 5 years of age, but only for those children who were exposed to high levels of contextual risk. This is inconsistent with previous research, as this measure clearly taps a positive dimension of the mother-child relationship and positive maternal behavior has generally been linked with more socially competent behavior. Some prior work does suggest, however, that mothers who are more solicitous (Rubin, Burgess, \& Hastings, 2002) or who tend to do things for their children to minimize conflict (Calkins \& Johnson, 1998) have children with higher levels of problem behavior. It may be that during toddlerhood, when demands for behavioral control and competent behavior increase, a greater degree of parental control rather than, or balanced with, greater warmth and responsiveness, is needed.

Thus, the findings indicated that both biological and behavioral resilience factors played a role in the decline of externalizing behavior problems over time. This normative pattern of decline, then, is clearly observable when children are displaying physiological and behavioral patterns that suggest good emotion regulation regardless of their risk status. Indeed, the relation of these resilience factors to adaptive emotion regulation skills suggests that they play a critical role in the normative development of such skills for all children, and so decrease the likelihood of significant behaviorproblems over time.

\section{Risk and resilience as predictors of the level and trajectories of internalizing behavior problems}

The association between contextual risk and the three levels of resilience factors and their impact on children's level and trajectories of internalizing behavior problems differ in some respects from the pattern of results found for externalizing behavior problems. In kindergarten, greater internalizing behavior problems were predicted by a number of factors, including higher contextual risk and resilience factors operating at each level of analysis. Specifically, greater baseline RSA, a more MRO between the mother and child, and lower frustration tolerance were all significantly related to the child's level of internalizing problems. These results suggest, to a certain extent, that there are some common factors that may exacerbate both internalizing and externalizing behavior problems. Indeed, we see evidence that basal 
RSA, indicative of reactivity, may play a role in the level of problem behavior displayed by the child. We also found that contextual risk was also moderated by children's temperamental persistence. When children were at greater risk when they were 2 years of age, lower persistence was linked to greater internalizing problems when they were 5 years old. This is consistent with the research indicating that interest/persistence is a behavioral characteristic that is clearly related to the management of emotion (Ruff \& Rothbart, 1996), which in turn, may lead to declines in internalizing symptoms over time.

With respect to the relational level of analysis, we observed that contextual risk was again moderated by MRO. Specifically, when children were at greater risk at 2 years of age and experienced a more MRO with their mother, they had higher internalizing problems at 5 years of age. Again, it may be that during toddlerhood when there are greater demands on the child to conform to rules and social standards that some maternal control may be needed to help the toddler learn to cope with the challenges of managing their behavior and emotions.

In examining the change in internalizing behavior across early childhood, a number of significant findings emerged, but the pattern of results were more complex than those found for children's externalizing behavior trajectories. Children's internalizing behavior problems decreased from 2 to 5 years of age when they had lower baseline RSA and lower levels of frustration tolerance. However, it needs to be noted that children with higher frustration tolerance actually had lower levels of internalizing behavior problems across early childhood. Children who exhibited lower levels of fear also experienced steeper declines in internalizing behavior problems over time, but this association was moderated by risk. Specifically, when contextual risk was high and children were less fearful, they had the highest level of internalizing behavior problems although these problems did decrease over time. In comparison, if contextual risk was high but children were more fearful, they had lower levels of internalizing behavior problems that also decreased over time. When contextual risk was low, however, there were differences in children's change over time in internalizing behaviors based on their fearlessness. Internalizing problems decreased when children were more fearful, but remained stable and at the lowest level of internalizing behavior problems. Thus, children's temperamental fearlessness has differential influences on children's internalizing behavior problems under conditions of low and high contextual risk. Overall, this suggests that for children living under conditions of high contextual risk, low levels of fearlessness may buffer to some extent the negative effects of that risk. It may be the case that some fear and anxiety is adaptive for young children in situations where there is likely to more uncertainty, as is the case when contextual risk is greater, as it may increase their level of alertness. The negative impact of rIsk on children's internalizing behaviors, however, was not completely overcome by this temperamental resilience factor.

Greater declines in internalizing behavior problems were also linked with a less MRO between the mother and child, although this association differed under conditions of high and low contextual risk. When contextual risk was high, children who experienced a more MRO with their mother had the greatest level of internalizing behavior problems that actually increased slightly over time. If contextual risk was high but children experienced a less mutually responsive relationship with their mother internalizing behavior problems were initially high but decreased over time. Again, our results are inconsistent with previous research that has found that a greater MRO is associated with children actually engaging in fewer problem behaviors. The need for balanced levels of maternal control within the context of a mutually positive and responsive relationship between the mother and child needs to be explored further in children who are at risk for behavior problems, particularly during the toddler and preschool years. It is important to highlight that MRO was only assessed when children were 2 years of age, a developmental period that has been noted for being particularly critical for early emotional and behavioral socialization. Indeed, research has indicated children are more likely to respond to parental directives within the context of a mutually responsive relationship (Kochanska \& Murray, 2000). It is possible that mothers with difficult 
toddlers, particularly given their young age, may try to use this parental strategy as a means of getting their children to behave in more appropriate ways. Future research that focuses on the dynamic associations between a MRO and children's behavior problems over time may provide a more nuanced view of this association.

In sum, our data indicate that risk status plays a powerful role in determining both the level of children's problem behavior at kindergarten entry and in terms of the rate of decline of those problems across time. However, regardless of a child's risk status, a number of within child resilience factors are operating to facilitate lower levels of problem behavior. Although in most cases in this study such factors did not appear to offset the risks associated with the child's environment, they are clearly operating in what Luther and colleagues term a protective fashion (Luthar et al., 2000), functioning in a positive way regardless of the child's level of risk. Thus, the data clearly support our hypothesis that several levels of within child factors may operate simultaneously in early development to support the emergence of behavioral competencies that decrease the likelihood of problem behavior.

An important issue that is not addressed by these data is whether and how these resilience factors might be integrated to influence children's capacity to overcome early risk. One potential mechanism integrating these within child resilience factors may be found in work that uses a neuroscientific framework to describe events in the developing brain and their role in emerging self-regulation (Bell \& Wolfe, 2004; Nigg \& Huang-Pollock, 2003; Posner \& Rothbart, 1994, 2000). Recent work in developmental neuroscience suggests there are two separate but closely related and potentially reciprocal subdivisions within the anterior cingulate cortex, one governing cognitive and attentional processes and the second governing emotional processes (Davidson, Putnam, \& Larson, 2000; Davis, Bruce, \& Gunnar, 2002). The integration of these neural processes over the course of early development have been linked to developments in self-regulatory ability that involve the effortful control of attention (Rueda, Posner, \& Rothbart, 2004). Moreover, the resilience dimensions identified as within child biological, behavioral, and relational have also been linked to the development of well-regulated behavior (Calkins, 2004; Calkins \& Fox, 2002). Thus, integration of these resilience factors may, in fact, be occurring at the neural level. Future work addressing the role of neural processes as resilience factors may provide a closer look at the integration of within-child processes that are observable at the physiological, behavioral, and relational level.

The study has a number of limitations that must be noted. First, the sample was overselected for externalizing behavior problems and thus may not be representative of community populations or at-risk samples in terms of internalizing symptomology. Second, the measures of behavior problems were exclusively parent report; given that many of the other study measures, particularly risk, were also parent report, there is a greater likelihood of single-rater bias. Important elements of the study, though, including physiological regulation and maternal behavior, would not have suffered from this problem. Third, the practical or clinical significance of relatively modest increases of decreases in level of problem behavior are difficult to determine. However, a change as small as $4 \mathrm{~T}$-score points on the CBCL may translate into the difference between a behavior that createsproblems for the child at home and in the peer environment, versus more positive behavior displayed in these environments. Such a difference may have implications for the child's day-to-day experience, regardless of whether such a change constitutes a clinically significantscore. Fourth, the degree to which the sample experienced contextual risk was possibly lower than is preferable in a study of risk for behaviorproblems. Although the risk index had sufficient variability, the average risk across the entire sample was rather low. Effects of risk were evident in the data; the degree of moderation by child resilience factors may have been minimized by the modest overall level of riskacross the sample.

This study extends the literature on early childhood behavior problems in a number of promising directions. First, although a number of studies address the risk factors for early problem behavior, and the resilience factors that may protect children from risk and facilitate 
successful adaptation, few studies have adopted an approach that address the multiple within child factors, across different levels of analysis, that may be operating. Here we argue for an approach to resilience factors operating within the child that takes into account three important levels of analysis and relies on observational methodologies to assess those levels. Our data clearly demonstrated that different factors may operate within the child to support successful development. The implications of this work for intervention and prevention work may be significant. Changes in the nature of the parent-child relationship, for example, may clearly play an important role in altering an expected outcome under conditions of contextual risk. Second, our study is also one of the first to examine the role of multiple dimensions of child behavioral characteristics, or temperament, which may be operating within the child.

\section{References}

Abidin, R. R. (1995). Manualfor the Parenting Stress Index. Odessa, FL: Psychological Assessment Resources.

Achenbach, T. M. (1991). Manual for the Child Behavior Checklist/4-18 and 1991 profile. Burlington, VT: University of Vermont, Department of Psychiatry.

Achenbach, T. M. (1992). Manual for the Child Behavior Checklist/2-3 and 1992 profile. Burlington, VT: University of Vermont, Department of Psychiatry.

Achenbach, T. M., \& Edelbrock, C. S. (1981). Behavioral problems and competencies reported by parents of normal and disturbed children aged four through sixteen. Monographs ofthe Societyfor Research in Child Development, 46(1, Serial No. 188).

Achenbach, T. M., \& Edelbrock, C. (1983). Manualfor the Child Behavior Checklist and revised Child Behavior Profile. Burlington, VT: University of Vermont, Department of Psychiatry.

Achenbach, T. M., Edelbrock, C., \& Howell, C. T. (1987) Empirically based assessment of the behavioral/emotional problems of 2- and 3-year-old children. Journal ofAbnormal Child Psychology, 15, 629-650.

Aiken, L. S., \& West, S. G. (1991). Multiple regression: Testing and interpreting interactions. London: Sage.

Anastopoulos, A. D., Guevremont, D. C., Shelton, T. L., \& DuPaul, G. J. (1992). Parenting stress among families with attention deficit hyperactivity disorder. Journal ofAbnormal Child Psychology, 20, 503-520.

Anthony, J. L, Lonigan, C. J., Hooe, E. S., \& Phillips, B. M (2002). An affect-based, hierarchical model of temperament and its relations with internalizing symptomatology. Journal of Clinical Child and Adolescent Psychology, 31, 480-490.

Barkley, R. A. (1990). A critique of current diagnostic criteria for attention deficit hyperactivity disorder: Clinical and research implications. Journal ofDevelopmental \& Behavioral Pediatrics, 11, 343-352.
Frustration tolerance is clearly important in helping a child adapt to the demands of the preschool period of development, as is fear tolerance; however, these characteristics clearly interact with a child's risk status. Third, although biological and behavioral characteristics may themselves be difficult to alter, we know from prior work that positive adaptations in the form of well-regulated behavior can help the child to manage subsequent developmental challenges in such a way as to increase the likelihood of a positive outcome (Calkins, 2002; Calkins et al., 1998). Fourth, the data demonstrate that, even in a relatively low-risk community sample, contextual risk is clearly a powerful force in predicting children's outcome, and one that is difficult to overcome despite within child characteristics that have been found to be associated with fewer difficulties in behavioral adaptation.

Bell, M. A., \& Wolfe, C. D. (2004). Emotion and cognition: An intricately bound developmental process. Child Development, 75, 366-370.

Biederman, J., Hirshfeld-Becker, D. R., Rosenbaum, J. F., Herot, C., Friedman, D., Snidman, N., et al. (2001). Further evidence of association between behavioral inhibition and social anxiety in children. American Journal of Psychiatry, 158, 1673-1679.

Booth, C. L., Rose-Krasnor, L., \& Rubin, K. H. (1991). Relating preschoolers' social competence and their mothers' parenting behaviors to early attachment security and high-risk status. Journal of Social and Personal Relationships, 8, 363-382.

Broidy, L. M., Nagin, D. S., Tremblay, R. E., Bates, J. E., Brame, B., \& Dodge, K. A. (2003). Developmental trajectories of childhood disruptive behaviors and adolescent delinquency: A six site, cross-sectional study. Developmental Psychology, 39, 222-245.

Calkins, S. D. (1994). Origins and outcomes of individual differences in emotion regulation. Monographs for the Society for Research on Child Development, 59(2-3, Serial No. 240), 53-72.

Calkins, S. D. (1997). Cardiac vagal tone indices of temperamental reactivity and behavioral regulation in young children. Developmental Psychobiology, 31, 125-135.

Calkins, S. D. (2004). Temperament and emotional regulation: Multiple models of early development. In M. Beauregard (Ed.), Consciousness, emotional selfregulation and the brain (pp. 35-59). Philadelphia, PA: John Benjamins.

Calkins, S. D., \& Dedmon, S. A. (2000). Physiological and behavioral regulation in two-year-old children with aggressive/destructive behavior problems. Journal of Abnormal Child Psychology, 2, 103-118.

Calkins, S. D., Dedmon, S. E., Gill, K. L., Lomax, L. E., \& Johnson, L. M. (2002). Frustration in infancy: Implica- 
tions for emotion regulation, physiological processes, and temperament. Infancy, 3, 175-197.

Calkins, S. D., \& Fox, N. A. (2002). Self-regulatory processes in early personality development: A multilevel approach to the study of childhood social withdrawal and aggression. Development and Psychopathology, 14,477-498.

Calkins, S. D., Graziano, P., \& Keane, S. P. (in press). Cardiac vagal regulation to emotional challenge differentiates among child behavior problem subtypes. Biological Psychology.

Calkins, S. D., \& Johnson, M. C. (1998). Toddler regulation of distress to frustrating events: Temperamental and maternal correlates. Infant Behavior and Development, 21, 379-395.

Calkins, S. D., \& Keane, S. P. (2004). Cardiac vagal regulation across the preschool period: Stability, continuity, and implications for childhood adjustment. Developmental Psychobiology, 45, 101-112.

Calkins, S. D., Smith, C. L., Gill, K. L., \& Johnson, M. C. (1998). Maternal interactive style across contexts: Relations to emotional, behavioral and physiological regulation during toddlerhood. Social Development, 7, 350369.

Campbell, S. B. (1995). Behavior problems in preschool children: A review of recent research. Journal of Child Psychology and Psychiatry, 36, 113-149.

Campbell, S. B. (1997). Behavior problems in preschool children: Developmental and family issues. Advances in Clinical Child Psychology, 19,1-26.

Campbell, S. B. (2002). Behavior problems in preschool children: Clinical and developmental issues (2nd ed.) New York: Guilford Press.

Campbell, S. B., Shaw, D. S., \& Gilliom, M. (2000). Early externalizing behavior problems: Toddlers and preschoolers at risk for later maladjustment. Development and Psychopathology, 12, 467-488.

Caspi, A., Henry, B., Mcgee, R., Moffitt, T., \& Silva, P. (1995). Temperamental origins of child and adolescent behavior problems: From age three to fifteen. Child Development, 66, 55-68.

Cicchetti, D. (1984). The emergence of developmental psychopathology, Child Development, 55, 1-7.

Cicchetti, D. (1993). Developmental psychopathology: Reactions, reflections, projections. Developmental Review, 13, 471-502.

Cicchetti, D., \& Dawson, G. (2002). Editorial: Multiple levels of analysis. Development and Psychopathology, 14,417-420.

Cicchetti, D., \& Rogosch, F. A. (1996). Equifinality and multifinality in developmental psychopathology. Development and Psychopathology, 8, 597-600.

Crowell, S. E., Beauchaine, T. P., Gatzke-Kopp, L., Sylvers, P., Mead, H., \& Chipman-Chacon, J. (2006). Autonomic correlates of attention-deficit/hyperactivity disorder and oppositional defiant disorder in preschool children. Journal of Abnormal Psychology, 115, 174178.

Cummings, E. M. (1995). Security, emotionality, and parental depression: A commentary. Developmental Psychology, 31, 425-427.

Cummings, E. M., Davies, P. T., \& Campbell, S. B. (2000). Developmental psychopathology and family process: Theory, research, and clinical issues. New York: Guilford Press.

Cummings, M., Ianotti, R. J., \& Zahn-Waxler, C. (1989). Aggression between peers in early childhood
Individual continuity and developmental change. Child Development, 60, 887-895.

Curtis, J. W., \& Ciccetti, D. (2003). Moving research on resilience into the 21 st century on resilience into the 21st century: Theoretical and methodological considerations in examining the biological contributors to resilience. Development and Psychopathology, 15 $773-810$

Davidson, R. J., Putnam, K. M., \& Larson, C. L. (2000). Dysfunction in the neural circuitry of emotion regulation-A possible prelude to violence. Science, 289 , 591-594.

Davis, E. P., Bruce, J., \& Gunnar, M. R. (2002). The anterior attention network: Associations with temperamen and neuroendocrine activity in 6-year-old children Developmental Psychobiology, 40, 43-56.

Deater-Deckard, K., Atzaba-Poria, N., \& Pike, A. (2004) Mother- and father-child mutuality in Anglo and Indian British families: A link with lower externalizing problems. Journal of Abnormal Child Psychology, 32, 609-620.

Deater-Deckard, K., \& Petrill, S. A. (2004). Parentchild dyadic mutuality and child behavior problems: An investigation of gene-environment processes. Journal of Child Psychology and Psychiary, 45, 1171-1179.

DeGangi, G., DiPietro, J., Greenspan, S., \& Porges, S. W. (1991). Psychophysiological characteristics of the regulatory disordered infant. Infant Behavior and Development, 14, 37-50.

Derogatis, L. R. (1986). Manualfor the Symptom Checklist 90-Revised (SCL-90R). Baltimore, MD: Author.

Dumas, J. E., \& LaFreniere, P. J. (1993). Mother-child relationships as sources of support or stress: A comparison of competent, average, aggressive, and anxious dyads. Child Development, 64, 1732-1754.

El-Sheikh, M. (2005). Stability of respiratory sinus arrhythmia in children and young adolescents. Developmental Psychobiology, 46, 307-317.

Fox, N. A., Calkins, S. D., Porges, S. W., Rubin, K. Coplan, R. J., Stewart, S., et al. (1995). Frontal activation asymmetry and social competence at four years of age. Child Development, 66,1770-1784.

Garcia-Coll, C., Kagan, J., \& Reznick, J. (1984). Behavioral inhibition in young children. Child Development, 55, 505-529.

Gardner, F. E. (1987). Positive interaction between mothers and conduct-problems children: Is their training for harmony as well as fighting? Journal of Abnormal Child Psychology, 15, 283-293.

Gardner, F. E. (1989). Inconsistent parenting: Is there evidence for a link with children's conduct problems? Journal of Abnormal Child Psychology, 17, 223233.

Gardner, F. E. (1994). The quality of joint activity between mothers and their children with behaviour problems. Journal of Child Psychology and Psychiatry, 35, 935948

Garson, G .D. (2006). Data implicationsfor missing values Retrieved February 1, 2006, from http://www2.chass. ncsu.edu/garson/pa765/ missing.htm

Goldberg, S., Gotowiec, A., \& Simmons, R. J. (1995) Infant-mother attachment and behavior problems in healthy and chronically ill preschoolers. Development and Psychopathology, 7, 267-282.

Goldsmith, H. H. (1996). Studying temperament via construction of the Toddler Behavior Assessment Ouestionnaire. Child Develonment. 67. 218-235. 
Hart, C. H., DeWolf, D. M., Wozniak, P., \& Burts, D. C. (1992). Maternal and paternal disciplinary styles: Relations with preschoolers' playground behavioral orientations and peer status. Child Development, 63, 879892.

Hartup, W. W. (1974). Aggression in childhood: Developmental perspectives. American Psychologist, 29, 337341

Hartup, W. W. (1996). The company they keep: Friendships and their developmental significance. Child Development, 67,1-13.

Hollingshead, A. B. (1975). Four-Factor Index of Social Status. New Haven, CT: Yale University.

Huffman, L. C., Bryan, Y. E., del Carmen, R., Pederson, F. A., Doussard-Roosevelt, J. A., \& Porges, S. W. (1998). Infant temperament and cardiac vagal tone: Assessments at twelve weeks of age. Child Development, 69, 624-635.

Kagan, J., \& Snidman, N. (1991). Temperamental factors in human development. American Psychologists, 46,856862

Keane, S. P., \& Calkins, S. D. (2004). Predicting kindergarten peer social status from toddler and preschool problem behavior. Journal of Abnormal Child Psychology, 32,409-423.

Keiley, M. K., Lofthouse, N., Bates, J. E., Dodge, K. A., \& Pettit, G. S. (2003). Differential risks of covarying and pure components in mother and teacher reports of externalizing and internalizing behavior across ages 5 to 14. Journal of Abnormal Child Psychology, 31, 267-283.

Keenan, K., Shaw, D. S., Delliquadri, E., Giovannelli, J., \& Walsh, B. (1998). Evidence for the continuity of early problem behaviors: Application of a developmental model. Journal of Abnormal Psychology, 26,441-452.

Kochanska, G. (1997). Mutually responsive orientation between mothers and their young children: Implications for early socialization. Child Development, 68, 94-112.

Kochanska, G., Forman, D. R., \& Coy, K. C. (1999). Implications of the mother-child relationship in infancy for the socialization in the second year of life. Infant Behavior and Development, 22, 249-265.

Kochanska, G., \& Murray, K. Y. (2000). Mother-child mutually responsive orientation and conscience development: From toddler to early school age. Child Development, 71, 417-431.

Kopp, C. B. (1982). Antecedents of self-regulation: A developmental perspective. Developmental Psychology, 18,199-214

Luthar, S., Cicchetti, D., \& Becker, B. (2000). The construct of resilience: A critical evaluation and guidelines for future work. Child Development, 71, 543-562.

Lyons-Ruth, K., Alpern, L., \& Repacholi, B. (1993). Disorganized infant attachment classification and maternal psychosocial problems as predictors of hostileaggressive behavior in the preschool classroom. Child Development, 64, 572-585.

Maccoby, E. E. (1984). Socialization and developmental change. Child Development, 55, 317-328.

Masten, A. S., Best, K. M., \& Garmezy, N. (1990). Resilience and development: Contributions from the study of children who overcome adversity. Development and Psychopathology, 2, 425-444.

Mathijssen, J., Koot, H. M., \& Verhulst, F. C. (1999). Predicting change in problem behavior from child and family characteristics and stress in referred children and adolescents. Development and Psychopathology, $11,305-320$
McFadyen-Ketchum, S. A., Bates, J. E., Dodge, K. A., \& Pettit, G. S. (1996). Patterns of change in early childhood aggressive-disruptive behavior: Gender differences in predictions from early coercive and affectionate mother-child interactions. Child Development, 67, 24172433.

McLoyd, V. C. (1990). The impact of economic hardship on Black families and children: Psychological distress, parenting, and socioemotional development. Child Development, 61, 311-346.

Merikangas, K. R., Swendsen, J. D., Preisig, M. A., \& Chazan, R. Z. (1998). Psychopathology and temperament in parents and offspring: Results of a family study. Journal ofAffective Disorders, 51, 63-74.

Miller, N. B., Cowan, P. A., Cowan, C. P., Hetherington, E. M., \& Clingempeel, W. G. (1993). Externalizing in preschoolers and early adolescents: A cross-study replication of a family model. Developmental Psychology, 29, 3-18.

Morris, A. S., Silk, J. S., Steinberg, L., Sessa, F. M., Avenevoli, S., \& Essex, M. J. (2002). Temperamental vulnerability and negative parenting as interacting of child adjustment. Journal of Marriage and Family, 64,461-471.

Mun, E. Y., Fitzgerald, H. E., Von Eye, A., Puttler, L. I., \& Zucker, R. A. (2001). Temperamental characteristics as predictors of externalizing and internalizing child behavior problems in the context of high and low parental psychopathology. Infant Mental Health Journal, 22, 393-415.

Nagin, D., \& Tremblay, R. (1999). Trajectories of boys' physical aggression, opposition, and hyperactivity on the path to physically violent and nonviolent juvenile delinquency. Child Development, 70, 1181-1197.

Nigg, J. T., \& Huang-Pollock, C. L. (2003). An early-onset model of the role of executive functions and intelligence in conduct disorder/delinquency. In B. B. Lahey, T. E. Moffit, \& A. Caspi (Eds.), Causes of conduct disorder and juvenile delinquency (pp. 227-253). New York: Guilford Press.

Ollendick, T. H., Shortt, A. L., \& Sander, J. B. (2005). Internalizing disorders of childhood and adolescence. In J. E. Maddux \& B. A. Winstead (Eds.), Psychopathology: Foundationsfora contemporary understanding (pp. 353376). Mahwah, NJ: Erlbaum.

Owens, E. B., \& Shaw, D. S. (2003). Predicting growth curves of externalizing behavior across the preschool years. Journal of Abnormal Child Psychology, 31, 575-590.

Patterson, G. R. (1982). Coercive family process. Eugene, OR: Castalia.

Patterson, G. R., DeBaryshe, B. D., \& Ramsey, E. (1989). A developmental perspective on antisocial behavior. American Psychologist, 44, 329-335.

Pettit, G. S., Bates, J. E., \& Dodge, K. E. (1993). Family interaction patterns and children's conduct problems at home and school: A longitudinal perspective. School Psychology Review, 22, 403-420.

Phillips, B. M., Lonigan, C. J., Driscoll, K., \& Hooe, E. S. (2002). Positive and negative affectivity in children: A multitrait-multimethod investigation. Journal of Clinical Child and Adolescent Psychology, 31, 465-479.

Porges, S. W. (1985). US Patent 4,520,944. Washington, DC: US Patent and Trademark Office.

Porges, S. W. (1991). Vagal tone: Autonomic mediator of affect. In J. A. Garber \& K. A. Dodge (Eds.), The development of affect regulation and dysregulation (pp. 111-128). New York: Cambridge University Press. 
Porges, S. W. (1996). Physiological regulation in high-risk infants: A model for assessment and potential intervention. Development and Psychopathology, 8, 43-58.

Porges, S. W. (2001). The polyvagal theory: Phylogenetic substrates of a social nervous system. International Journal of Psychophysiology, 42, 123-146.

Porges, S. W. (2003). The polyvagal theory: Phylogenetic contributions to social behavior. Physiology \& Behavior, 79, 503-513.

Porges, S. W., Doussard-Roosevelt, J. A., \& Maita, A. K. (1994). Vagal tone and the physiological regulation of emotion. Monographs of the Society for Research in Child Development, 59(2-3, Serial No. 240), 167186.

Porges, S. W., Doussard-Roosevelt, J. A., Portales, A. L., \& Greenspan, S. I. (1996). Infant regulation of the vagal "brake" predicts child behavior problems: A psychobiological model of social behavior. Developmental Psychobiology, 29, 697-712.

Posner, M. I., \& Rothbart, M. K (1994). Attentional regulation: From mechanism to culture. In P. Bertelson \& P. Eelen (Eds.), International perspectives on psychological science: Vol. 1. Leading themes (pp. 41-55). Hillsdale, NJ: Erlbaum.

Posner, M. I., \& Rothbart, M. K. (2000). Developing mechanisms of self-regulation. Development and Psychopathology, 12, 427-441.

Prior, M., Smart, D., Sanson, A., \& Oberklaid, F. (1993). Sex differences in psychological differences in psychological adjustment from infancy to 8 years. Journal of the American Academy of Child \& Adolescent Psychiatry, 32, 291-304.

Raudenbush, S. W., \& Bryk, A. S. (2002). Hierarchical linear models: Applications and data analysis methods (2nd ed.) Thousand Oaks, CA: Sage.

Renken, B., Egeland, B., Marvinney, D., Mangelsdorf, S., \& Sroufe, L. A. (1989). Early childhood antecedents of aggression and passive-withdrawal in early elementary school. Journal of Personality, 57, 257-281.

Richards, J. E. (1987). Infant visual sustained attention and respiratory sinus arrhythmia. Child Development, 58, 488-496.

Richters, J. E. (1997). The Hubble hypothesis and the developmentalist's dilemma. Development and Psychopathology, 9, 193-199.

Rogosa, D., Brant, D., \& Zimowski, M. (1982). A slow growth curve approach to the measurement of change. Psychological Bulletin, 92, 726-748.

Rothbart, M. K., \& Bates, J. E. (1998). Temperament. In W. Damon (Ser. Ed.) \& N. Eisenberg (Vol. Ed.) Handbook of child psychology: Vol. 4. Social, emotional, and personality development (5th ed., pp. 105176). New York: Wiley.

Rottenberg, J., Saloman, K., Gross, J. J., \& Gotlib, I. H. (2005). Vagal withdrawal to a sad film predicts subsequent recovery from depression. Psychophysiology, 42, 277-281.

Rubin, K. H., \& Asendorpf, J. B. (1993). Social withdrawal, inhibition, and shyness in childhood. Hillsdale, NJ: Erlbaum.

Rubin, K. H., Booth, C., Rose-Krasnor, L., \& Mills, R. S. L. (1995). Social relationships and social skills: A conceptual and empirical analysis. In S. Shulman (Ed.), Close relationships and socioemotional development (pp. 63-94). Norwood, NJ: Ablex.

Rubin, K. H., Burgess, K. B., \& Hastings, P. D. (2002). Stability and social-behavioral consequences of tod- dler's inhibited temperament and parenting behaviors. Child Development, 73, 483-495.

Rubin, K. H., Coplan, R. J., Fox, N. A., \& Calkins, S. D. (1995). Emotionality, emotion regulation and preschoolers' social adaptation. Development and Psychopathology, 7, 49-62.

Rueda, R. M., Posner, M. I., \& Rothbart, M. K. (2004). Attentional control and self-regulation. In R. F. Baumeister \& K. D. Vohs (Eds.), Handbook of self-regulation: Research, theory, and applications (pp. 283-300). New York: Guilford Press.

Ruff, H. A., \& Rothbart, M. K. (1996). Attention in early development: Themes and variations. London: Oxford University Press.

Rutter, M. (1987). Psychosocial resilience and protective mechanisms. American Journal of Orthopsychiatry, 57, 316-331.

Rutter, M. (2002). The interplay of nature, nurture, and developmental influences: The challenge ahead for mental health. Archives of General Psychiatry, 59, 996-1000.

Sameroff, A., Gutman, L. M., \& Peck, S. C. (2003) Adaptation among youth facing multiple risks: Prospective research findings. In S. S. Luthar (Ed.), Resilience and vulnerability: Adaptation in the context of childhood adversities (pp. 364-391). New York: Cambridge University Press

Seifer, R. (2003). Young children with mentally ill parents: Resilient developmental systems. New York: Cambridge University Press.

Seifer, R., Schiller, M., Sameroff, A., Resnick, S., \& Riordan, K. (1996). Attachment, maternal sensitivity, and infant temperament during the first year of life. Developmental Psychology, 32, 12-25.

Shaw, D. S., Gilliom, M., Ingoldsby, E. M., \& Nagin, D. (2003). Trajectories leading to school-age conduct problems. Developmental Psychology, 39, 189-200.

Shaw, D., Owens, E., Giovannelli, J., \& Winslow, E. (2001). Infant and toddler pathways leading to early externalizing disorders. Journal ofthe American Academy of Child \& Adolescent Psychiatry, 40, 36-43.

Shaw, D., Owens, E., Vondra, J., Keenan, K., \& Winslow, E. (1996). Early risk factors and pathways in the development of early disruptive behavior problems. Development and Psychopathology, 4, 679-700.

Shaw, D. S., Winslow, E. B., Owens, E. B., Vondra, J. I., Cohn, J. F., \& Bell, R. Q. (1998). The development of early externalizing problems among children from low-income families: A transformational perspective. Journal of Abnormal Child Psychology, 26, 95-107.

Singer, J. D., \& Willett, J. B. (2003). Applied longitudinal data analysis: Modeling change and event occurrence. New York: Oxford University Press.

Sroufe, A. L., \& Rutter, M. (1984). The domain of developmental psychopathology. Child Development, 55,17-29.

Stifter, C. A., \& Fox, N. A. (1990). Infant reactivity: Physiological correlates of newborn and 5-month temperament. Developmental Psychology, 26, 582588.

St. Jonn Seed, M., \& Weiss, S. (2002). Maternal expressed emotion as a predictor of emotional and behavioral problems in low birth weight children. Issues in Mental Health Nursing, 23, 649-672.

Suess, P. E., Porges, S. W., \& Plude, D. J. (1994). Cardiac vagal tone and sustained attention in school-age children. Psychophysiology, 31, 17-22.

Tremblay, R. E. (2000). The development of aggressive behavior during childhood: What have we learned in the 
past century? International Journal of Behavioral Development, 24, 129-141.

Wilson, B., \& Gottman, J. (1996). Attention-The shuttle between emotion and cognition: Risk, resiliency, and physiological bases. In E. Hetherington \& E. Blechman (Eds.), Stress, coping and resiliency in children and families. Mahwah, NJ: Erlbaum.

Winslow, E. B., Shaw, D. S., Bruns, H., \& Kiebler, K (1995). Parenting as a mediator ofchild behavior prob- lems and maternal stress, support, and adjustment. Paper presented at the Biennial Meeting of the Society for Research in Child Development, Indianapolis, IN.

Zahn-Waxler, C., Klimes-Dougan, B., \& Slattery, M. J. (2000). Internalizing problems of childhood and adolescence: Prospects, pitfalls, and progress in understanding the development of anxiety and depression. Development and Psychopathology, 12, 443-466. 